PORTIONS OF THIS REPORT ARE ILLEGIBLE. II has been reproduced from the best availahle copy to permit the broedest possible avail-

LA-10136-MS

unility.

UC-28

losued: July 1984

$L A--10136-11 S$

DE84 017078

\title{
LAMPF Transition-Region Mechanical Fabrication
}

E. D. Bush, Jr.

J. D. F. Gallegos

R. Harrison

V. E. Hart
W. T. Hunter

S. E. Rislove

J.R. Sims

W. J. Van Dyke 


\section{DISCLAIMER}

This report was prepared as an account of work sponsored by an agency of the United States Government. Neither the United States Government nor any agency thereof, nor any of their employees, makes any warranty, express or implied, or assumes any legal liability or responaibility for the aceuracy, completeness, or usefulness of any information, apparatus, product, or process disclosed, or represents that its use would not infringe privately owned rights. Reference herein to any specific commercial product, process, or service by trade name, trademark, manufacturer, or atherwise does not necessarily constitute or imply its endorsement, recommendation, or favoring by the United States Government or any agency thereuf. The views and opinions of authors expressed herein do not necessarily state or reflect those of the United States Government or any agency thereor. 
by

E. D. Bush, Jr., J. D. F. Gallegos, R. Harrisou, V. E. Hart, W. T. Hunter, S. E. Rislove, J. R. Sims, and W. J. Van Dyke

ABSTRACT

The primary purpose of the new Transition Region (TR-II) is to optimize the phase matching of the $\mathrm{H}^{+}$and $\mathrm{H}^{-}$beams during simultaneous transport. TR-II incorporates several design improvements that include larger aperture, a straight beam track, greater beam-path length adjustments, and utility lines integrated with the support system. The "close pack" density of mag.ets and beam-line hardware required innovative solutions to magnet design and mounting, vacuum manifolding, and ...llity routing. Critical magnet placement was accomplished using a new three-dimensional aligngent system that does rea1-time vector ca1culations on a computer with input from two digital theodolites. All assembly and a large fraction of the mechanical fabrication were done by LAMFF personnel. The TR-II has been operational since September 1983 and routinely transports production beams up to 900- $\mu$ A current with no major problems.

I. INTRODUCTION

Design, construction, and initial installation of the 201-MHz drift-tube linac (DTL) and 805-MHz side-coupled 1inac (SCL) had started before the idea of simultaneous acceleration of $\mathrm{H}^{+}$and $\mathrm{H}^{-}$beams was proposed. 1 The very Iimited 
space between the DTL and SCL had been Irreversibly established when desiga was started on the original Transition Region.

The purpose of the Transition Region is to match the outpur of the DTL to the input of the SCL. An additional path length of approximately $8 \mathrm{~cm} \mathrm{is}$ required to establish a proper phase relationship between the two beams. This phase change allows both beams to be accelerated simultaneously through the SCL.

The original Transition Region shown In Fig. 1 had several limitations, which caused operational problems and limited independent matching of the $\mathrm{H}^{+}$and $\mathrm{H}^{-}$beams. The new Transition Region (TR-II) was desigred to eliminate theee problems and incorporates the following major features: large aperture, straight track, additional diagnostics, space on long track for beam-path length adjustments, quadrupole magnets on all three tracks for independent matching, and utility lines integrated with the support structure for a neater installation. A schematic of TR-II is shown In Fig. 2.

This report covers the engineering design, construction, and installation of the TR-II.

II. CONCEPTUAL DESIGN

The basic configuration of TR-II shown In FIg - 2 was concelved by Andrew A. Browman with analytical support provided by oscar Sander.2,3

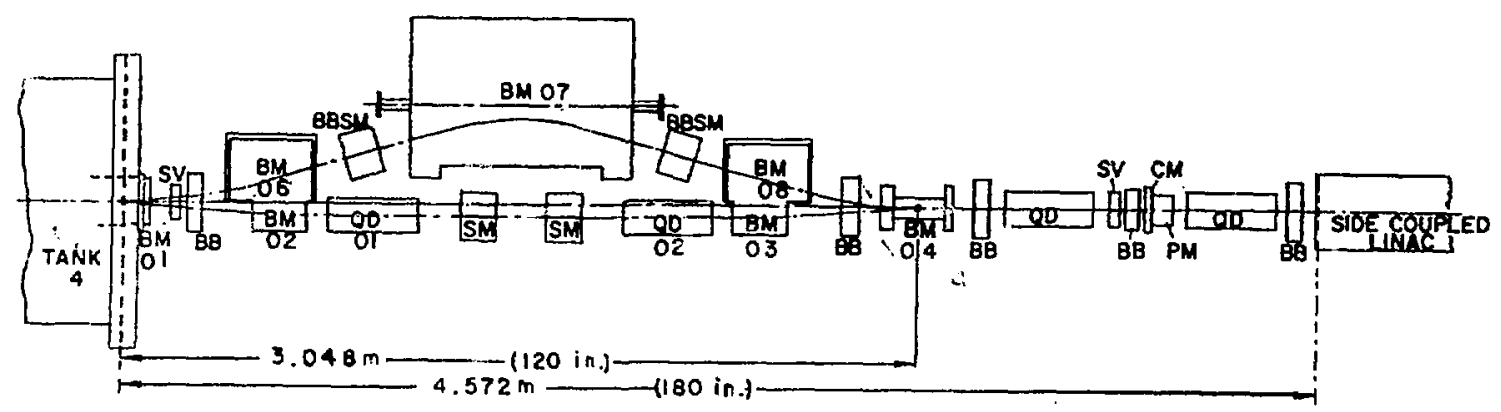

Fig. 1 .

Original Transition Region. 


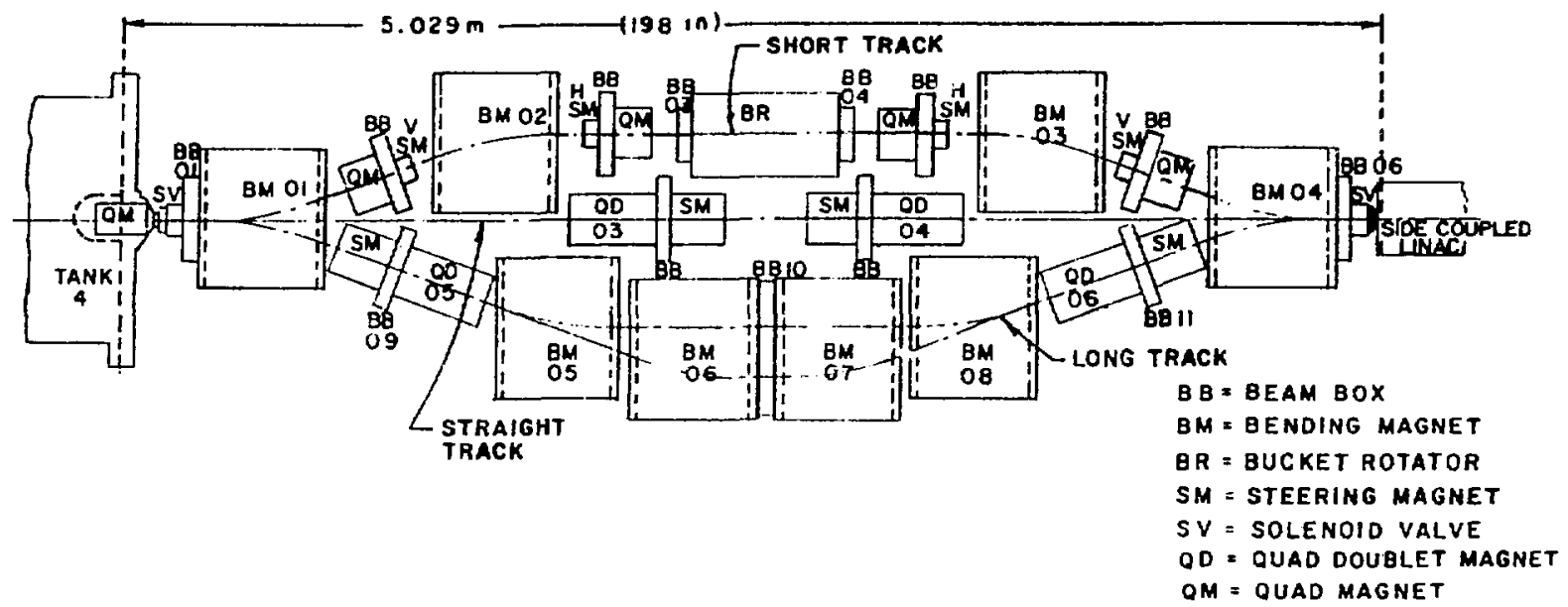

F1g. 2.

New TR-II.

Preliminary magnet design estimates indicated that the existing space between the DTL and SCL would not be adequate for TR-II. The required spacing was obtalned by moving the complete $805-\mathrm{MHz}$ module 5 downstream a distance of $0.46 \mathrm{~m}$.

At this point the design became an iterative process to satisfy the major beam-transpoit conditions. These requirements were beam-matching criteria, with magnetic fields sufficiently low to minimize $\mathrm{H}^{-}$stripping and still allow enough space for all of the required beam-1ine devices.

The two beams are deflected $20^{\circ}$ by $\mathrm{BMO}$ and restored to the accelerator axis by BM04. The short-path BM02 and BM03 magnets operate at fixed fields to provide $20^{\circ}$ bend angles. The path length in the long track can be varied by adjusting bending magnets BM05, 06, 07, and 08, which have a combined bending angle of $40^{\circ}$. This is accomplished by powering all of the coll turns in BM01, 02, 03, and 04, and half of the turns in BM05, 06, 07, and 08, with one power supply at a constant current. The second power supply is varlable and powers the other half of the turns in BM05, 06, 07, and 08. The ampere turns add in BM06 and 07 and buck in BM05 and 08 to provide a total variation in path length of approximately $\pm 2 \mathrm{~cm}$. A schematic of power supply connactions is shown in Fig. 3. 


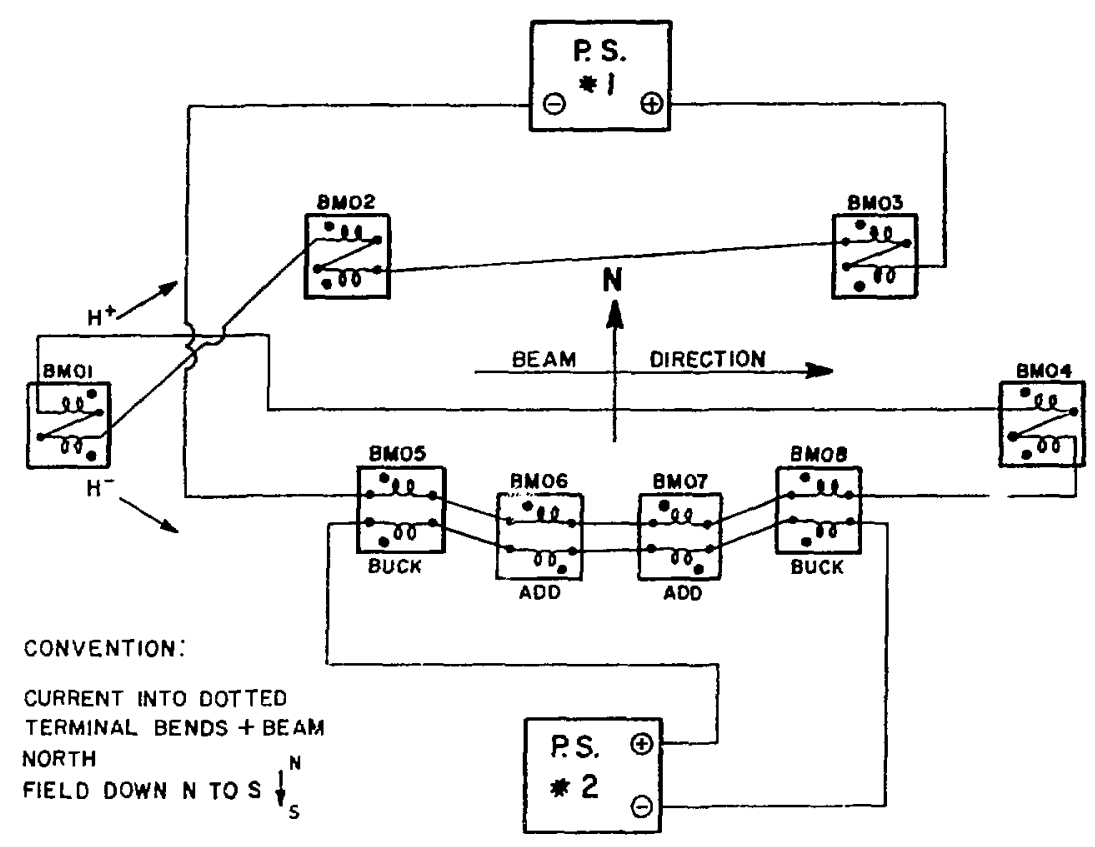

Fig. 3.

Schematic of power for bending magnets.

III. MECHANICAL DESIGN AND FABRICATION

An important goal for TR-II was to make it as uncluttered and serviceable as possible. Details of major systems are given in the following paragraphs, with a complete drawing list shown in Appendix A.

\section{A. Scheduling}

Separate programs were written using the ASA program and E-Z Pert Charts, to maintain project schedules for TR-II fabrication and installation activities. Inftial input of time and manpower requirements was obtained from the person responstble for each task or set of tasks. A general meeting of those involved was held to review and consolidate the scheduling data, which were then put into the computer program to run the printouts and charts. A few meetings were held at appropriate times to update the complete schedule. A typical fabrication printout and Installation bar chart are shown in Figs. 4 and 5. 
Approximately 25 individuals were involved in managing separate specialized tasks. Task completions were required on time and in specific order. This scheduling activity proved to be most helpful and effective in the successful completion of the TR-II.

\section{B. Magnet Design}

The magnets dominate the space avallable in the new TR. Many design iterations were conducted to satisfy all of the constraints imposed by the beam transport, space avallable, and magnetic fleld 11mitations, in addition to providing magnets that were compatible with all of the other devices in the TR.

Small magnets dictate the use of high-current densities in the conductor and direct water cooling. High currents are required when using the relatively large hollow conductors that allow unrestricted flow, hence reducing the possibility of plugged water circuits.

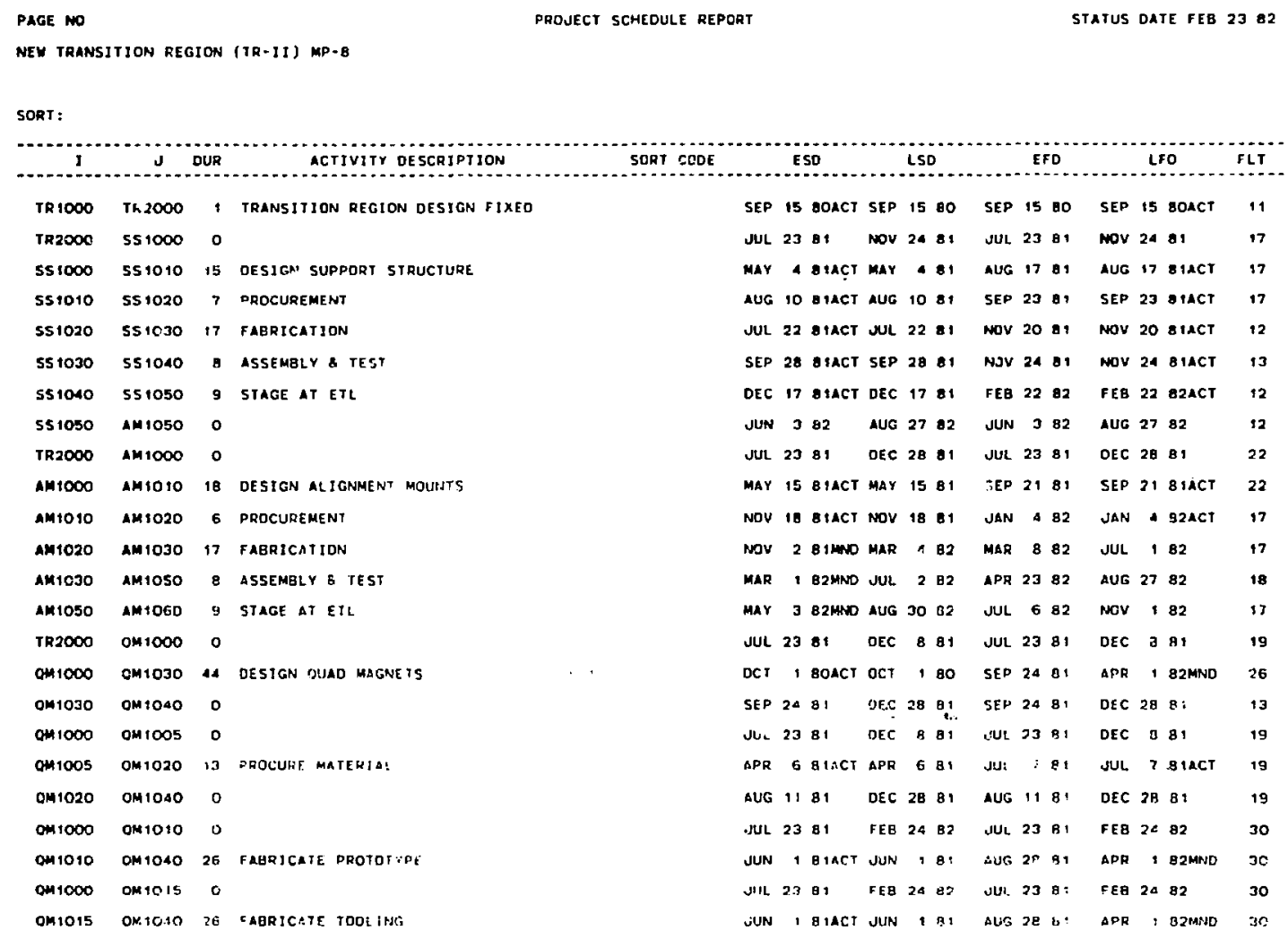

Fig. 4 .

Fabrication printout (sample page). 


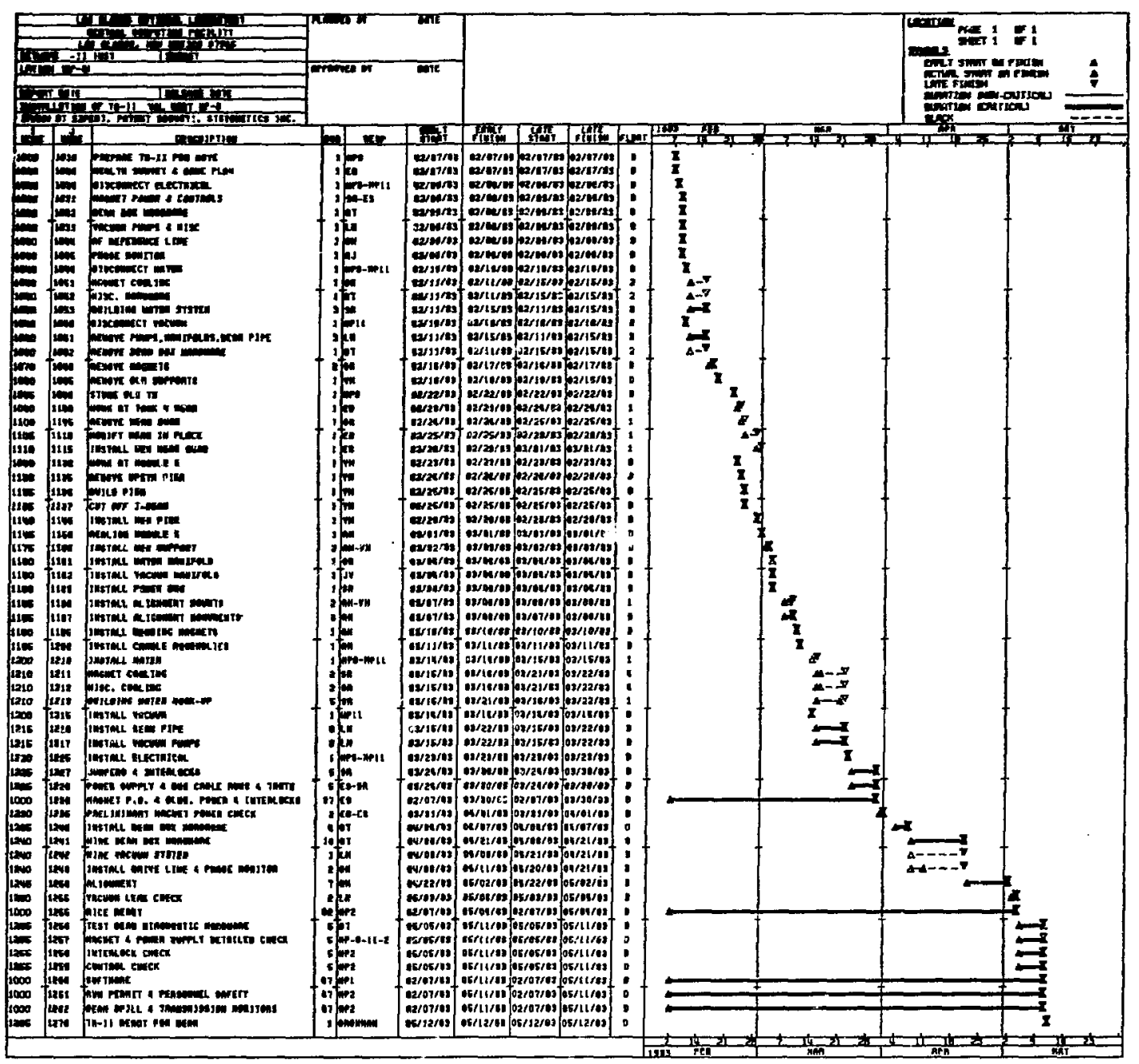

Fig. 5.

Installation bar chart.

The TR-II 18 made up of elght bending magnets, twelve quad magnets, and twelve steering magnets. There is but one design for each type of magnet, and their measured operating characteristics must be sufficiently alike to be interchangeable. This approach minimizes fabrication costs and permits a mintmum spares inventory. The magnet gaps were determined from the clear aperture requirements, the vacuum beam-pipe deflection for the worst case for each type of magnet; and the clearance necessary for alignment. The computer program POISSON was used to establish the magnet 1ron and coll configurations necessary to achieve the required fleld quality, integral strength, and 
effective length requirements. In view of the number of magnets and the demanding field quality, a prototype of each type was fabricated and measured prior to production.

Any of the magnets can be disassembled for maintenance or removed without disturbing the vacuum systems. The magnet cores were machined from $\mathrm{C} 1006 \mathrm{steel}$. Conventional coll fabrication techniques were used: braided fiberglass sleeve Insulation over hollow copper conductor, vacuum-cast in epoxy resin. All tooling, ccil winding, and molds were fabricated by MP-8 personnel; the Plastics Section of MST-6 performed the coll casting. The MP- 8 Alignment Section was Involved in the design of all devices at their inception to ensure proper provisions for alignment.

Because space was at a premium, water-cooled electrical jumpers were useó on all three types of magnets to simplify the installation. The jumpers carry the current from the main bus bars and, in the case of the quadrupole and steering magnets, also provide cooling water. The bending-magnet cooling requirement was great enough to require separate water manifolds.

To permit easy maintenance, the electrical and water connections were located for convenient access in the beam chaninel.

\section{Bending Magnets}

The bending marnets occupy more space in the new TR than do any of the other devices; hence their design and construction were the most demanding.

The maximum allowable fleld of $11.9 \mathrm{kG}$ across a gap of $5.7 \mathrm{~cm}$ with an $\mathrm{fB} \cdot \mathrm{dl}$ of $510 \mathrm{kG} \cdot \mathrm{cm}$ was specified. In addition the field integral was to be uniform over the volume $\pm 1.5-\mathrm{cm}$ high by $\pm 8.9-\mathrm{cm}$ wide to within $0.1 \%$ in all magnets (including the spare) In order to be interchangeable. In the full "bucked" coll mode, the magnets must yield a near-zero field. POISSON was used to determine the magnet gerwatry necessary to achieve the fleld uniformity, integral strength, effective length, and the full-current minimum-field requirement.

A picture-frame configuration was selected because it has relatively uniform fields and long effective length for a given overall magnet length: To minimize the length, the top and bottom coil sections were limited to two layers each. The coll design had to produce sufficlently uniform flelds in both adding and bucking modes. The coil had to be divided into two sections with equal numbers of turns. This constraint 1imited the coll design to a total number of turns $N=8,16,24,32, \ldots$, etc. As shown in $\mathrm{Fig} .6$, several coll 


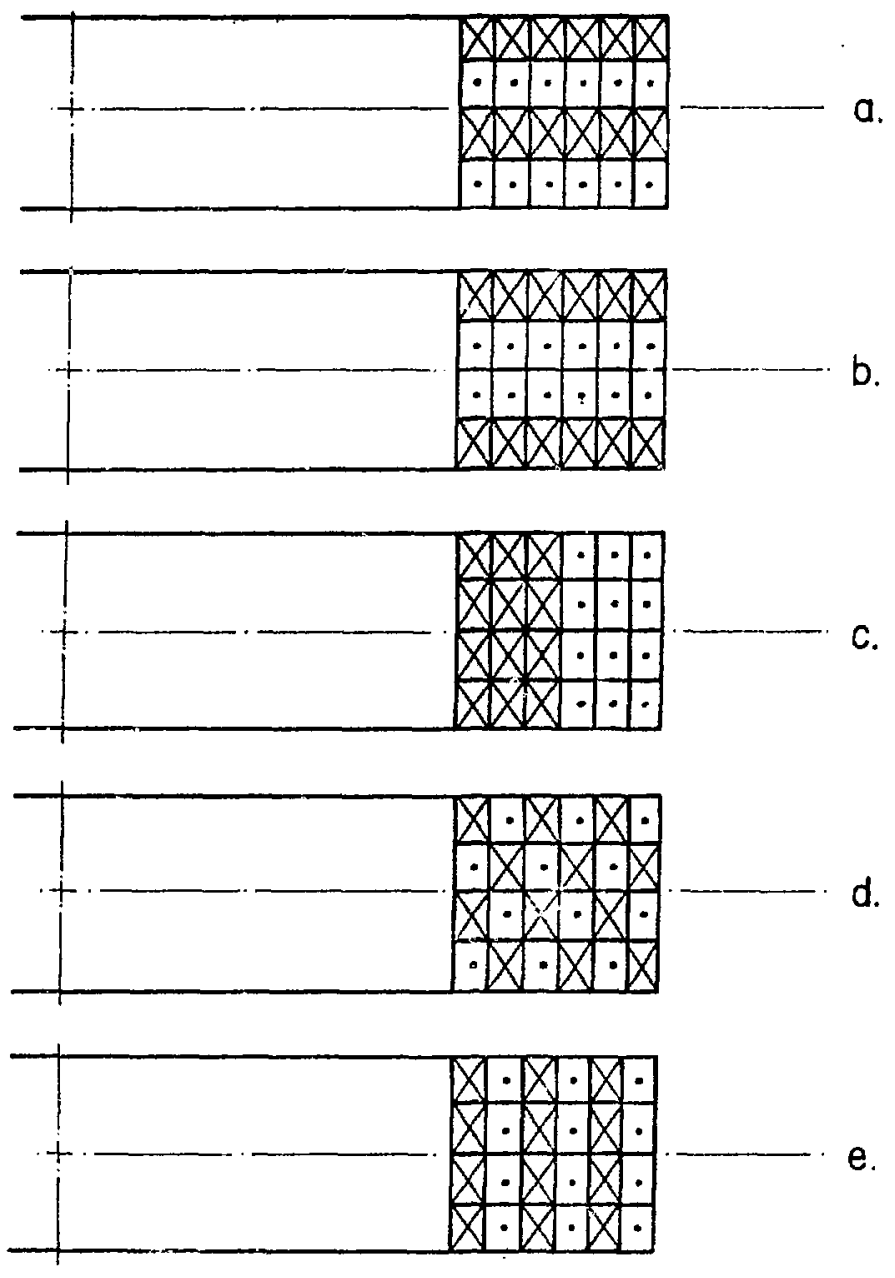

FIg. 6 .

Bending-magnet coil configurations evaluated.

configurations were evaluated; configuration " $e$ " was selected because it satisfied POISSON, appealed intultively, and was relatively easy to wind.

Based on this model, a prototype magnet was constructed and field measurements were performed with an NMR probe, rotating coll, filp colls, and Ha11 probes. The rotating coll measuring $\left(\mathrm{Bx}^{2}+\mathrm{B}^{2}\right)^{1 / 2}$ was stepped in $6.4-\mathrm{mm}$ increments through the magnet. These data were then integrated numerically to yield $\delta B=d 1$. The flip coil was used to verify the data but was too large to permit "off axis" measurements. To achleve field uniformity, it was necessary to chamfer the pole ends. Figure 7 shows the results of chamfering for integral 


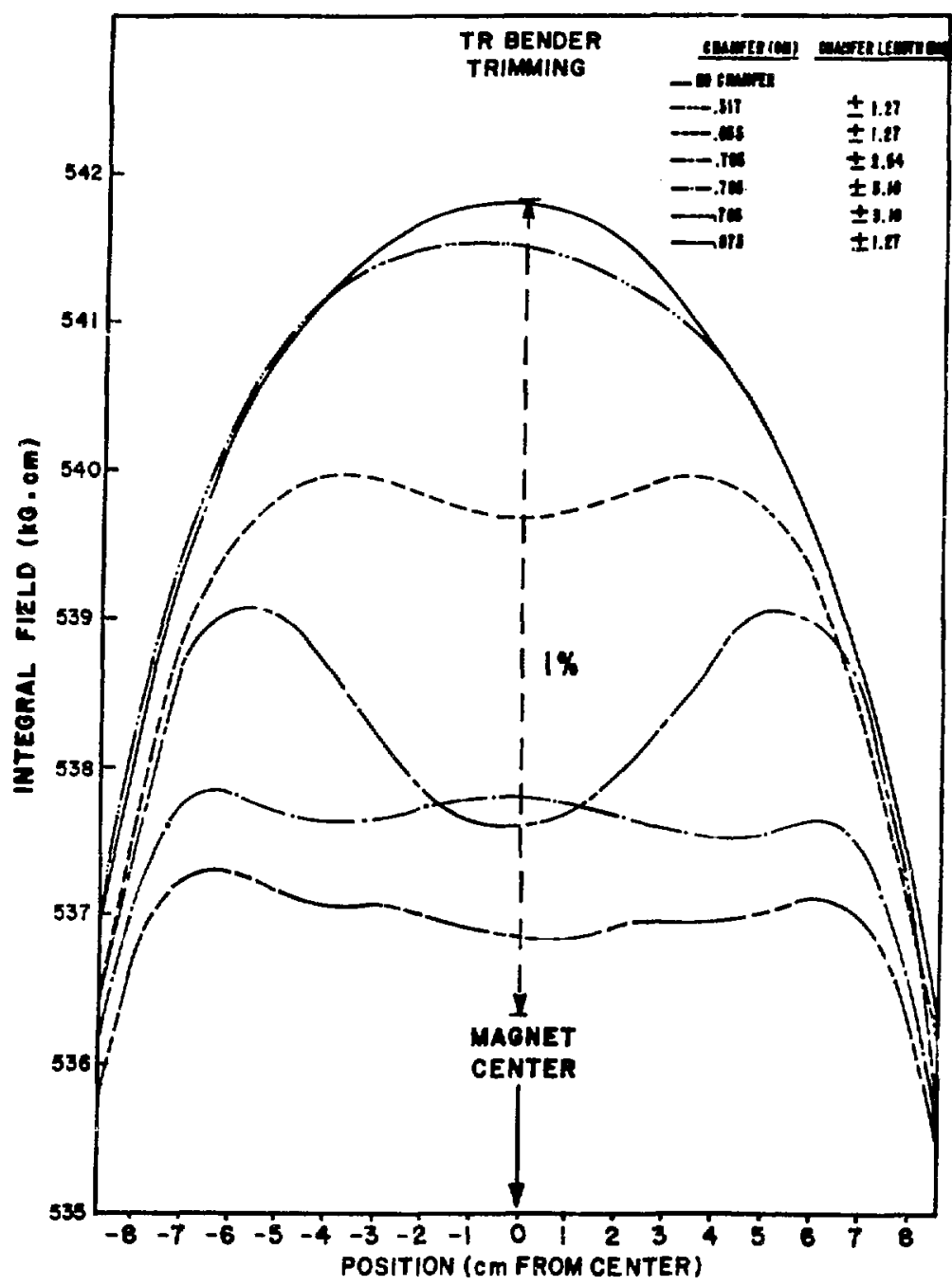

F1g. 7.

Bending magnet pole trimming.

uniformity along the midplane axis. Based upon these data, it was decided to procure elght production magnets plus one spare. Most of the necessary tooling was complete after fabricating the prototype. The conductor was formed by MST-6, Metal Fabrication, by drawing our LAMPF standard 11.8-mm square by 7.0-mm 1.d. copper conductor through a "Turks Head" to a $7.62 \mathrm{~mm}$ by $12.2 \mathrm{~mm}$ rectangular section. The bending magnets operate at $\sim 2200 \mathrm{~A}$ with a current density of about $2910 \mathrm{~A} / \mathrm{cm}^{2}$; consequently. each turn is a separately cooled circuit. Each six-turn, two-layer pancake was wound flat with bare conductor properly spaced, then the ends were formed $90^{\circ}$ with special tooling. Each turn 
then was insulated with bralded glass sleeve and the turn-to-turn connections were made by brazing small copper spacers at specific crossover locations. The vertical straps on the side of the magnet permit connecting the magnets for oneor two-power supply operation. The design permits the magnet to be disassembled for installation of a beam pipe without risconnecting the cooling hoses.

All nine bending magnets were measured as accurately as possible at the $20^{\circ}$ and $0^{0}$ fleld levels. A detalled description of these measurements is given in a memorandum written by $A$. Browman. 4 Table $I$ shows the measurements of the effectlve length and $J B \cdot d l$ through the central path when all magnets are powered at the nominal operating current. In the full bucking mode, a fleld integral of $1.5 \mathrm{kG} \cdot \mathrm{cm}$ or $0.3 \%$ of the full adding mode of $516 \mathrm{kG} \cdot \mathrm{cm}$ was measured. The magnets match each other to the $0.1 \%$ level, indicating good quality control during construction. Correcting individual magnets was not required to achieve this unfformity. Figure 8 shows more detalled measurements performed on one of the production bending magnets--In this case, measurements were made both vertically and horizontally from the central axis. All data in this figure were normalized by dividing $\delta B \cdot d l$ by $\int B \cdot d l$ through the center of the magnet. The rectangular area in the figure with a height of $\pm 0.1 \%$ and width of $\pm 90 \mathrm{~mm}$ shows the portion of the aperture that should 1le within the $0.1 \%$ field uniformity requirement.

TABLE I

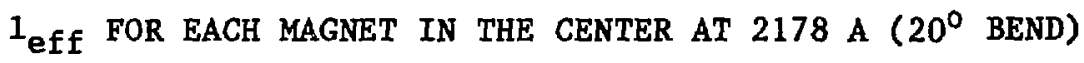

\begin{tabular}{|c|c|c|}
\hline Magnet & $l_{\text {eff }}(\mathrm{cm})$ & $\rho \mathrm{B} \cdot \mathrm{d} 1(\mathrm{kG} \cdot \mathrm{cm})$ \\
\hline TRBMI & 45.18 & 515.90 \\
\hline TRBM2 & 45.15 & 515.60 \\
\hline TRBM3 & 45.17 & 515.87 \\
\hline TRBM4 & 45.14 & 515.47 \\
\hline TRBM5 & 45.17 & 515.81 \\
\hline TRBM6 & 45.19 & 516.02 \\
\hline TRBM7 & 45.17 & 515.71 \\
\hline TRBM8 & 45.18 & 515.94 \\
\hline SPARE & 45.15 & 515.54 \\
\hline Average & $45.17 \pm 0.02$ & $515.76 \pm 0.19$ \\
\hline$\cdot$ & $( \pm 0.04 \%)$ & $( \pm 0.04 \%)$ \\
\hline
\end{tabular}




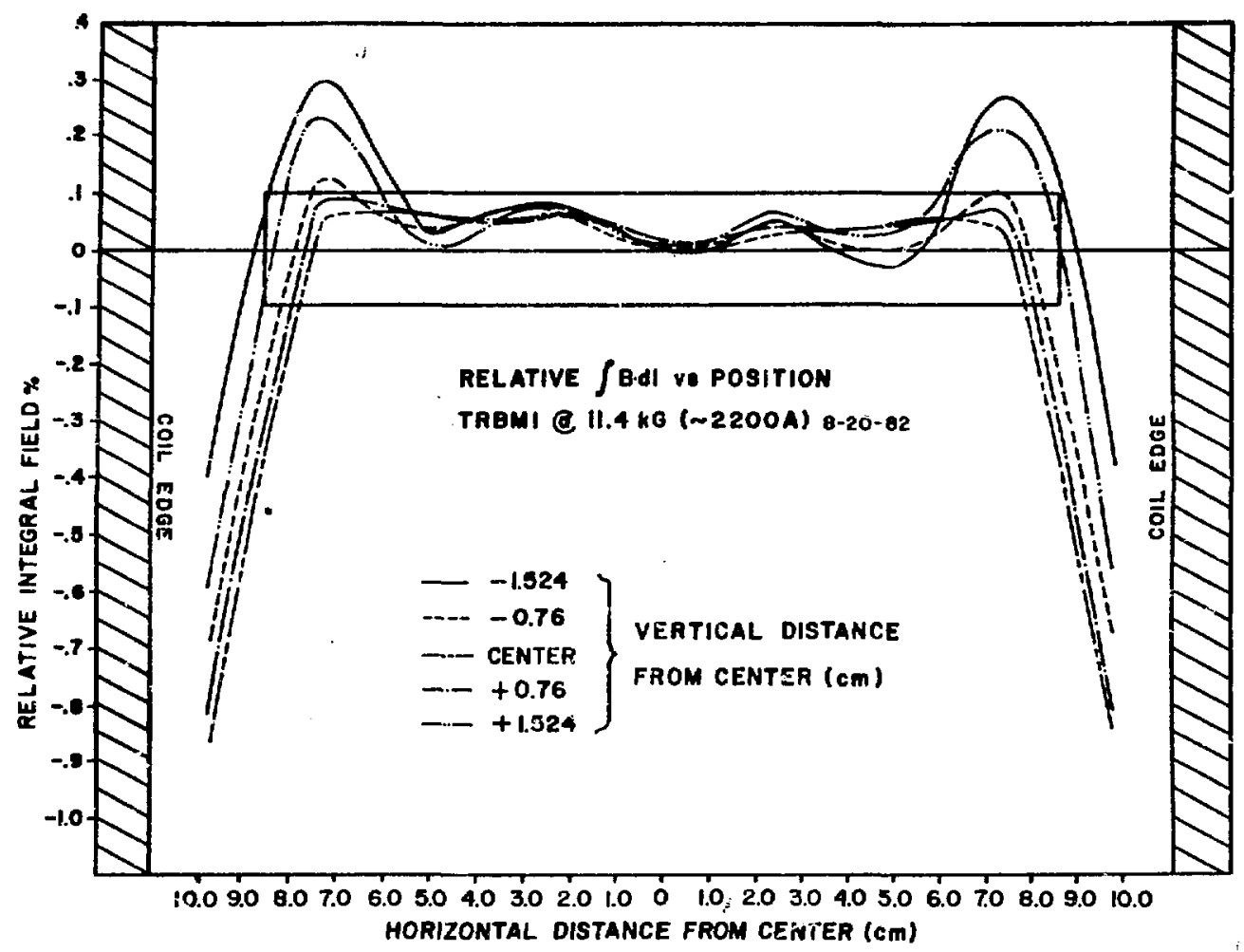

Fig. 8 .

TR BMO1 JB.dl vs position.

The effect of coil placement was not fully appreciated at the time of design. Consequently, the effective length was slightly longer than anticipated and there was some distortion of the magnet fields caused by the electrical terminations on one side of the magnet. The measured quality of tha magnets was deemed sufficient for the application; however, further improvements can be made by additional chamfering in the future if necessary. Some of the steps involved in the construction of the magnets, are shown in Figs. 9, 10, 11 and 12.

The characteristics of the bending magnets are shown in Table II. 


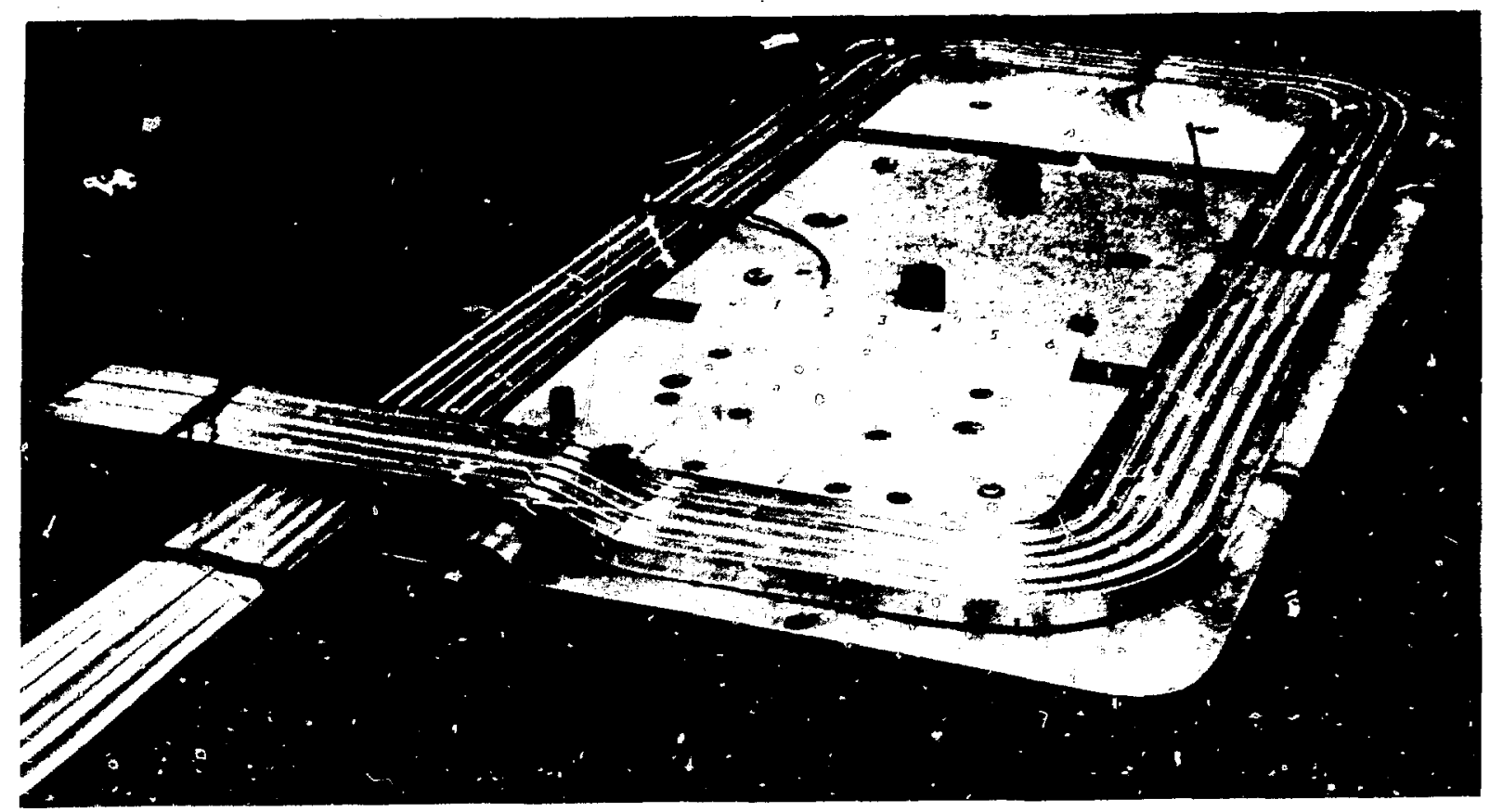

Fig. 9.

Bending magnet coll winding.

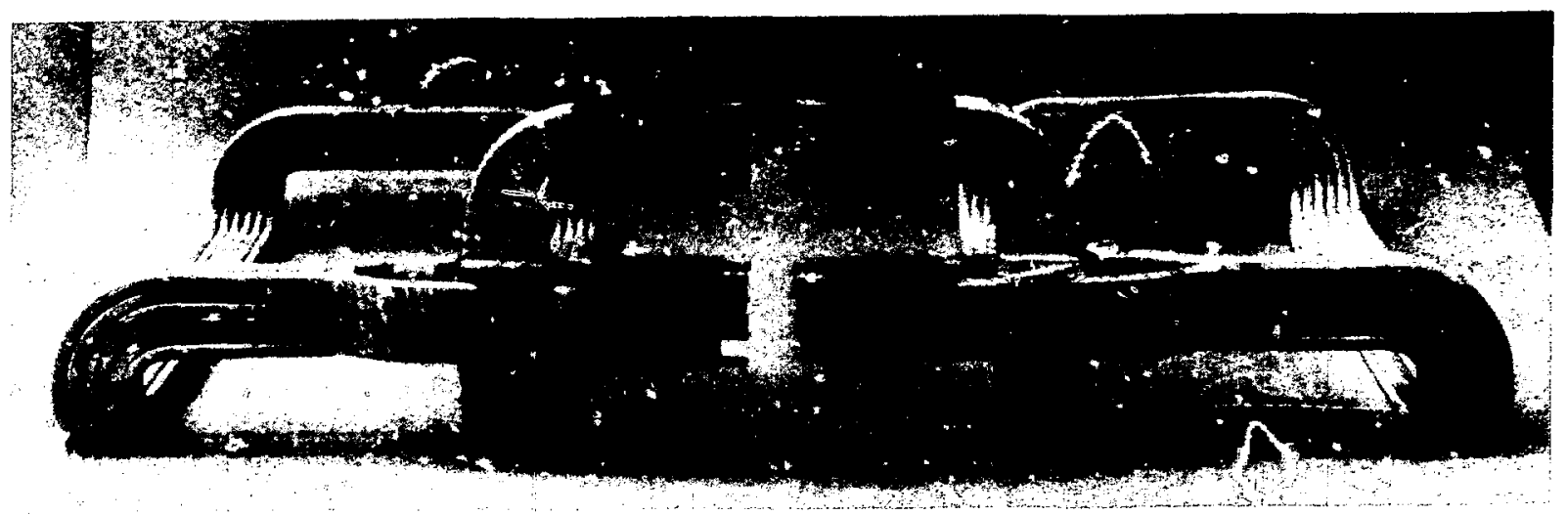

Fig. 10.

Bending magnet colls. 


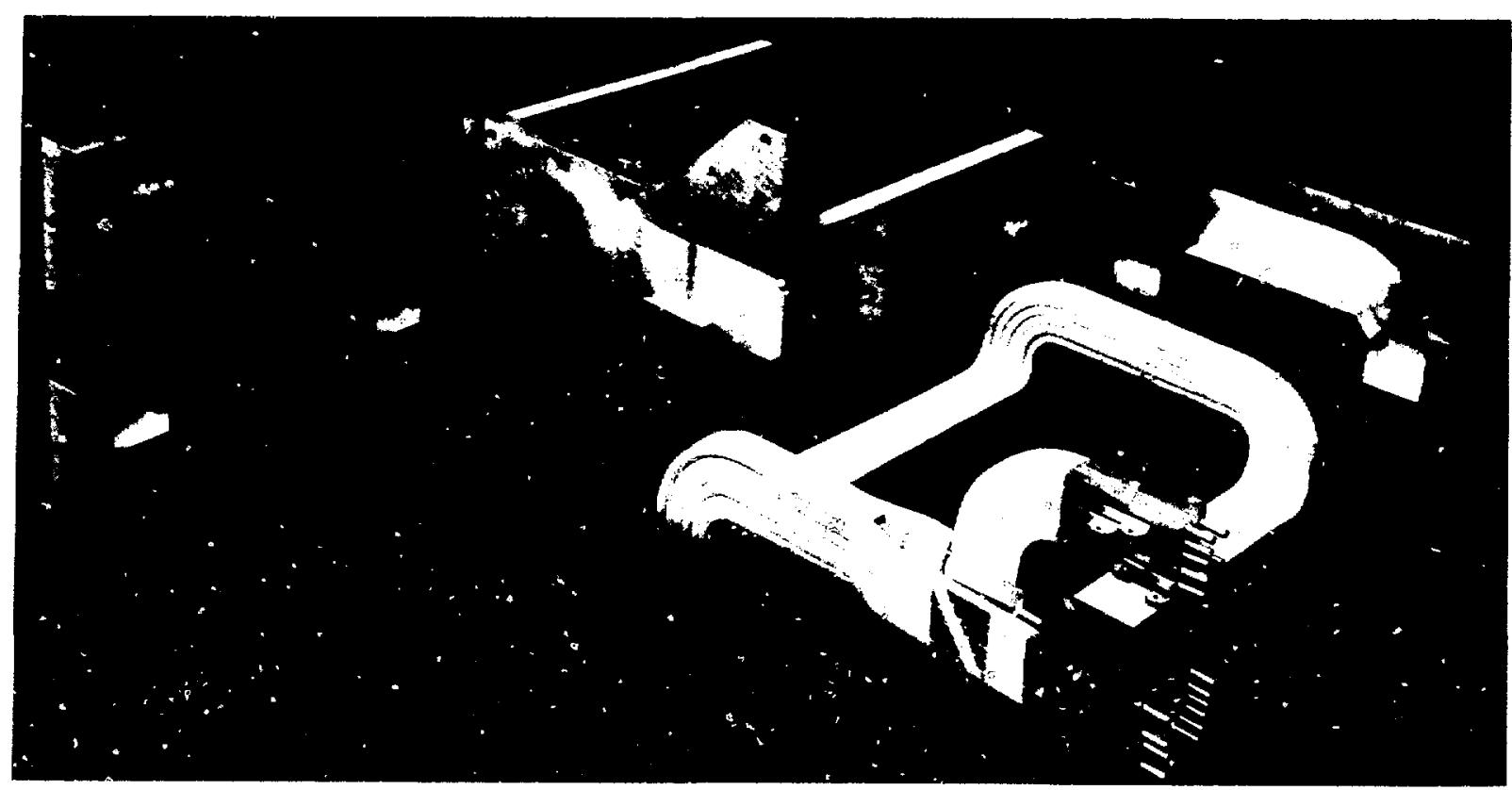

Fig. 11 .

Bending magnet wound coil and mold.

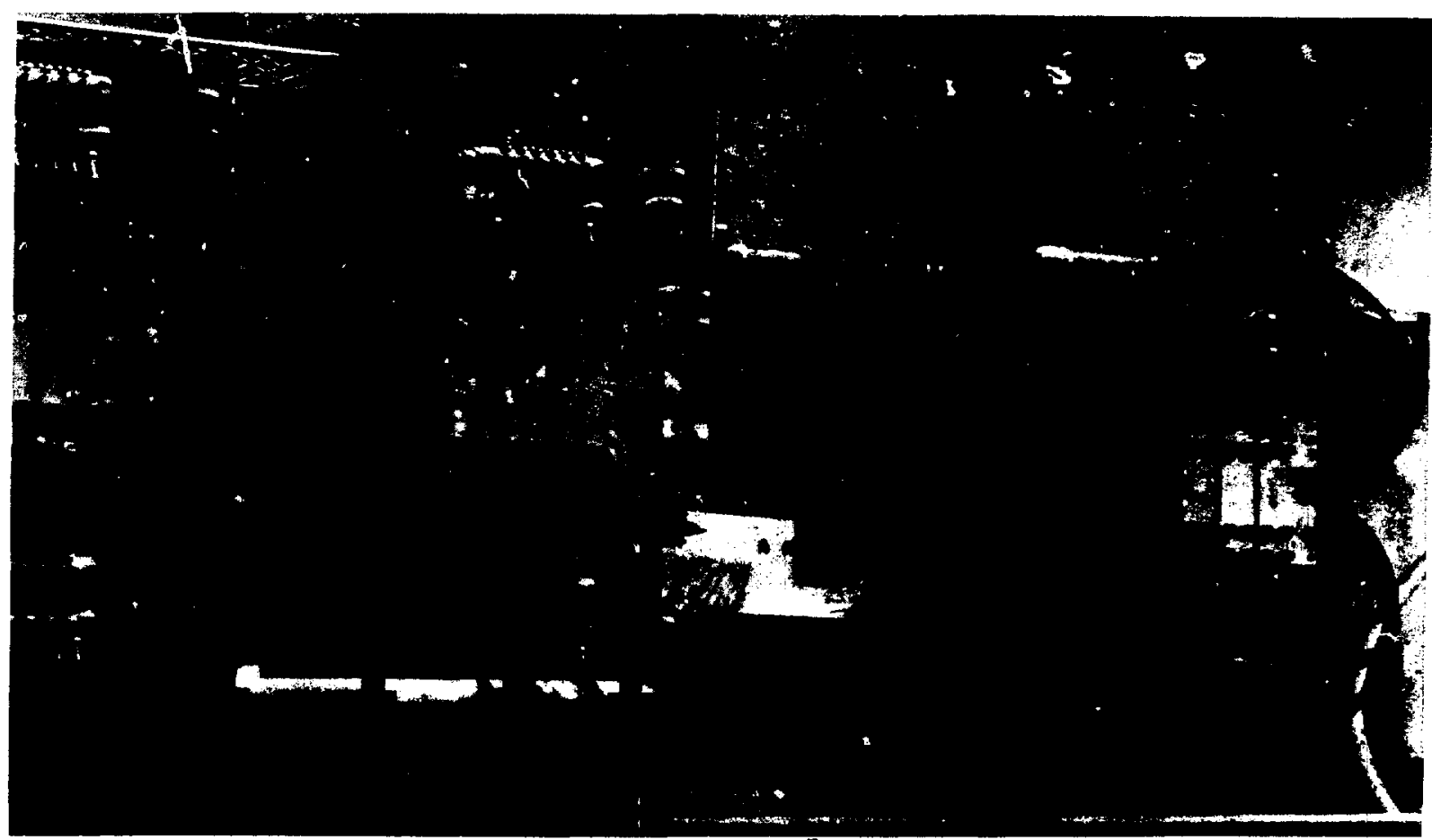

Fig. 12.

Bending magnet coil connections. 
TABLE II

BENDING-MAGNET PARAMETERS

$\begin{array}{lcl}\text { Aperture (gap by width) } & 57 \text { by } 217 & (\mathrm{~mm}) \\ \text { Pole length } & 388 & (\mathrm{~mm}) \\ \text { Field } & 11.418 & (\mathrm{kG}) \\ \text { Effective length } & 451.7 \pm 0.2 & (\mathrm{~mm}) \\ \text { S3.d1 } & 515.76 \pm 0.19 & (\mathrm{kG} \cdot \mathrm{cm}) \\ \text { Turns } & 24 & (\text { Turns }) \\ \text { Current } & 2178 & (A) \\ \text { Current density in sonductor } & 29.1 & \left(\mathrm{~A} / \mathrm{mm}^{2}\right) \\ \text { Resistance } & 0.00996 \pm 0.00003(\Omega) \\ \text { Voltage } & 21.69 & (\mathrm{~V}) \\ \text { Power } & 47.24 & (\mathrm{~kW}) \\ \text { Water flow } & 1.5 & (1 / \mathrm{s}) \\ \text { Pressure drop } & 340 & (\mathrm{kPa}) \\ \text { Temperature rise } & 8 & \left({ }^{\circ} \mathrm{C}\right) \\ \text { Weight } & 700 & (\mathrm{~kg})\end{array}$

D. Quadrupole Magnets

The magnetic requirements were determined by Oscar Sander using the beam transport code TRACE. ${ }^{3}$ Numerous tunes were evaluated, then narrowed down to a few that best met the criteria. Quadrupole strength SG:dl for the strongest focusing quad plus a 50\% safety factor was established as the design goal. The transport programs also established the clear aperture required through the beam pipe for the worst case. The pole diameter was fixed at $52 \mathrm{~mm}$ tu clear the 51-mm diameter $304 \mathrm{~L}$ stainless steel beam tube. Our magnet design was also required to match the existing TR power supplies, Imposing a 1000 A maximum-current limft on the design. POISSON was used to establish the first-order iron core and coll configurations and the ampere-turn requirement. Several design iterations were performed to achleve the desired gradient of about $3 \mathrm{kG} / \mathrm{cm}$ with the $1000-\mathrm{A}$ current criterion and the requirement that the colls be adequately cooled. Given the gradient and integral strength, the required effective magnetic length was established. The pole length was 
determined empirically, based on data acquired from measurements performed on numerous quadrupoles by the magnet-measuring crew in the past.

Twelve quads were required for the new $T R$ and it was decided to fabricate two spare units. Constructing and evaluating a prototype, in view of the number of magnets and the rather demanding field-quality requirements, was considered advisable. Most of the requirements were satisfled analytically, with the exception of the harmonic errors. Although the harmonic content was approximated by POISSON, the program is two-dimensional and cannot model end effects. This was the area where the full value of the prototype quad was realized.

The prototype quad was measured using two systems. One was a fast-rotating coll that could be positioned on the magnetic axis with its output measured using an HP Mode1 3582A wave analyzer. The coll assembly consisted of one coll much longer than the magnetic length of the quad and a short coll that permitted the measurement of the central and end flelds. The second system was a stepped coll that measured the integrated harmonics and determined the error between the magnetic and mechanical centers. Our initial approach was to use the traditional pole end chamfers to reduce the typical $N=6$ harmonics. To speed up the process, different chamfers were cut on each end of the poles.

Table III shows the effects of the different end chamfers on the $N=6$ and $\mathrm{N}=10$ harmonics. Harmonics determined by POISSON are also shown for comparison. It can be seen that although the $N=6$ effect was reduced by increasing the size of the chamfer, $N=10$ harmonics increased to an unacceptable value. The next approach used POISSON and the measured harmonic data to establish a new pole contour to minimize the undesirable harmonics. The result of this effort, shown in Table III, is labeled "modified poles." At this point, the integrated harmonic content. was considered acceptable, and we proceeded with the fabrication of the production magnet. The production quads were exact replicas of the last version of the prototype.

The quad was designed to have a minimum overall size and to permit convenient assembly, installation, and maintenance. The core is split vertically through the centerline, allowing magnet removal without disturbing the vacuum system. The colls are wound with $7.34-\mathrm{mm}$ square by $4.09-\mathrm{mm}$ inside-diameter copper conductors with elght turns per pole. The coll is made up of two sections with two poles per section wound from a single length of conductor also split on the vertical centerline. This geometry permitted easy 


\begin{tabular}{|c|c|c|c|c|c|c|}
\hline Chamfer (mm) & $\begin{array}{l}\mathrm{CN}=6 \\
\mathrm{ZN}=2\end{array}$ & $\begin{array}{l}\mathrm{C}^{\mathrm{N}}=10 \\
\mathrm{ZN}=2\end{array}$ & $\begin{array}{c}\text { ENDS } \mathrm{iN}=6 \\
\mathrm{zN}=2\end{array}$ & $\begin{array}{c}\text { ENDS } N=10 \\
Z N=2\end{array}$ & $\begin{array}{l}\int_{N=6}=6 \\
\underline{\mathrm{N}=2}\end{array}$ & $\begin{array}{l}S N=10 \\
Z / N=2\end{array}$ \\
\hline 0 & 0.91 & 0.84 & 10.54 & 0.17 & 5.1 & 1.68 \\
\hline $1.27-2.54$ & 0.91 & 0.77 & 8.96 & 0.66 & - & - \\
\hline $3.81-5.08$ & 0.99 & 0.98 & 5.97 & 1.68 & 3.68 & 2.57 \\
\hline $6.35-7.62$ & 1.03 & 0.96 & 3.91 & 1.71 & 2.74 & 2.70 \\
\hline
\end{tabular}

\begin{tabular}{|c|c|c|c|c|c|c|}
\hline 0 & $1.64 \%$ & $2.71 \%$ & $18.9 \%$ & $0.86 \%$ & 5.1 & $i .68$ \\
\hline $1.27-2.54$ & $1.64 \%$ & $2.48 \%$ & $16.1 \%$ & $2.11 \%$ & - & - \\
\hline $3.81-5.08$ & $1.78 \%$ & $3.16 \%$ & $10.69 \%$ & $5.42 \%$ & 3.68 & 2.57 \\
\hline $6.35-7.62$ & $1.85 \%$ & $3.09 \%$ & $7.01 \%$ & $5.50 \%$ & 2.74 & 2.70 \\
\hline
\end{tabular}

HARMONICS FROM POISSON COMPARED WITH STEP-COIL DATA

\begin{tabular}{|c|c|c|c|c|}
\hline & \multicolumn{2}{|c|}{ POISSON } & \multicolumn{2}{|c|}{ STEP-COIL } \\
\hline & $\begin{array}{r}\mathrm{N}=6 \\
z \mathrm{~N}=2 \\
\end{array}$ & $\begin{array}{l}\mathrm{N}=10 \\
\mathrm{ZN}=2\end{array}$ & $\begin{array}{l}f N=6 \\
Z N=2\end{array}$ & $\begin{array}{l}\mathrm{N}=10 \\
\mathrm{z}=2\end{array}$ \\
\hline Original Poles & -1.9 & -2.69 & 5.1 & 1.68 \\
\hline Modified Poles & +3.6 & -0.92 & 0.96 & 0.517 \\
\hline
\end{tabular}

col1 winding, formed two water circults with no splices, and el-strical connections that did not have conductors looping the beam. Some of the steps involved in the construction of the quad magnets are shown In Figs. 13, 14, 15 and 16.

All fourteen quads were measured extensively. A summary of these measurements is covered in detail in a memorandum written by A. Browman. 5 All magnets had similarly shaped excitation curves, although the magnitude varled as much as $0.08 \%$ between different magnets. The magnetic and mechanical centers were colncident to within $0.08 \mathrm{~mm}$. The two extremes in the normalized harmonic content measurements for the fourteen production magnets are shown in Table IV. The $B_{y}$ was measured using a Hall probe at $2.54-\mathrm{cm}$ offset from the centerline along the $Z$ axis to determine the effective length. Near the center of the magnet the effective length is $12.00 \pm 0.05 \mathrm{~cm}$, and it increases by about $0.4 \mathrm{~cm}$ from the center of the quad to the pole radius. Figure 17 presents a plot of SG.dI vs $I$. Dividing SG.dI by $1_{\text {eff }}$ glves the peak quadrupole gradient. The strengths ( $\int G \cdot d 1$ ) of all fourteen quad magnets were within $0.1 \%$ of each other. The typical parameters for the quadrupole magnets appear in Table $\mathrm{V}$. 


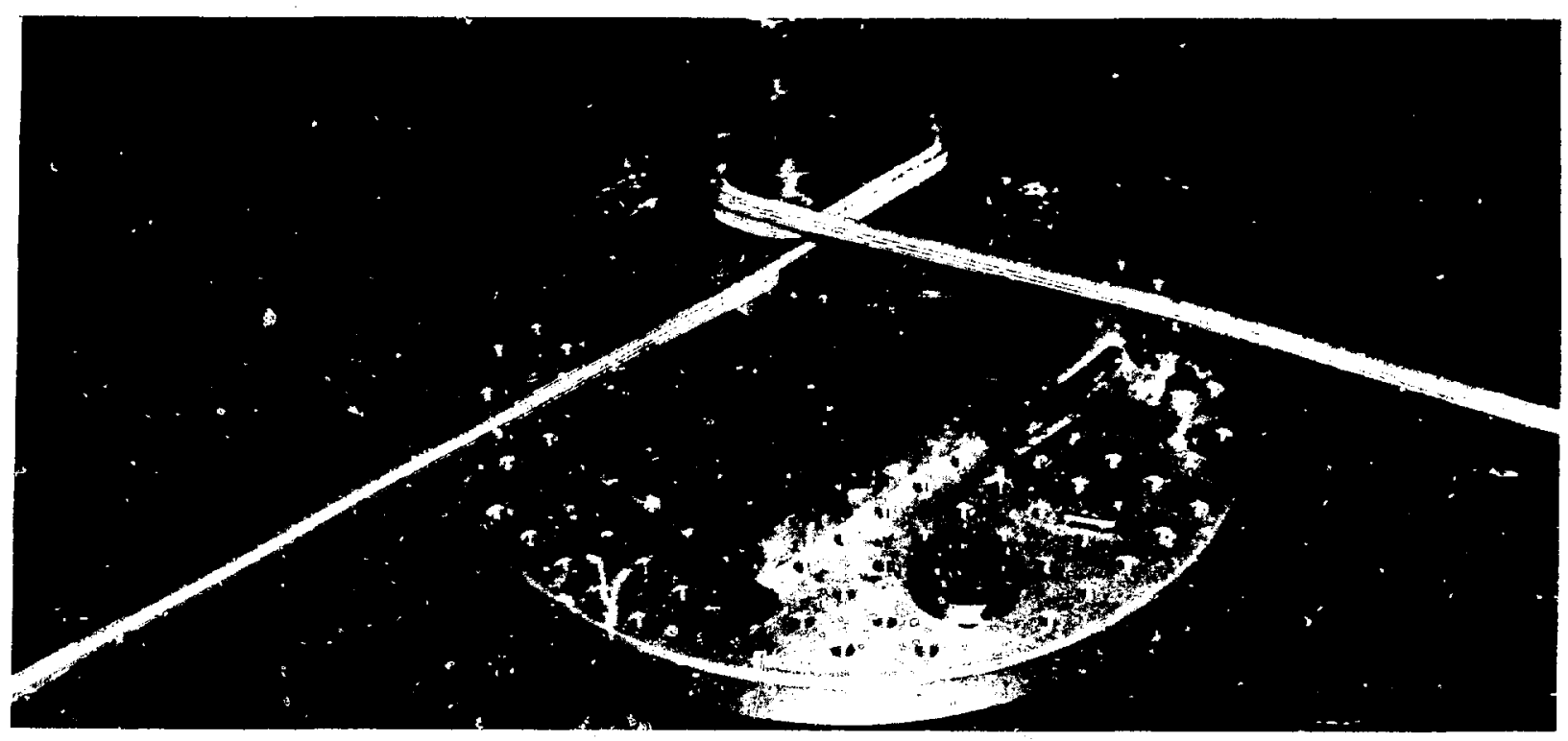

\section{Fig. 13.}

Quad coll winding (start).

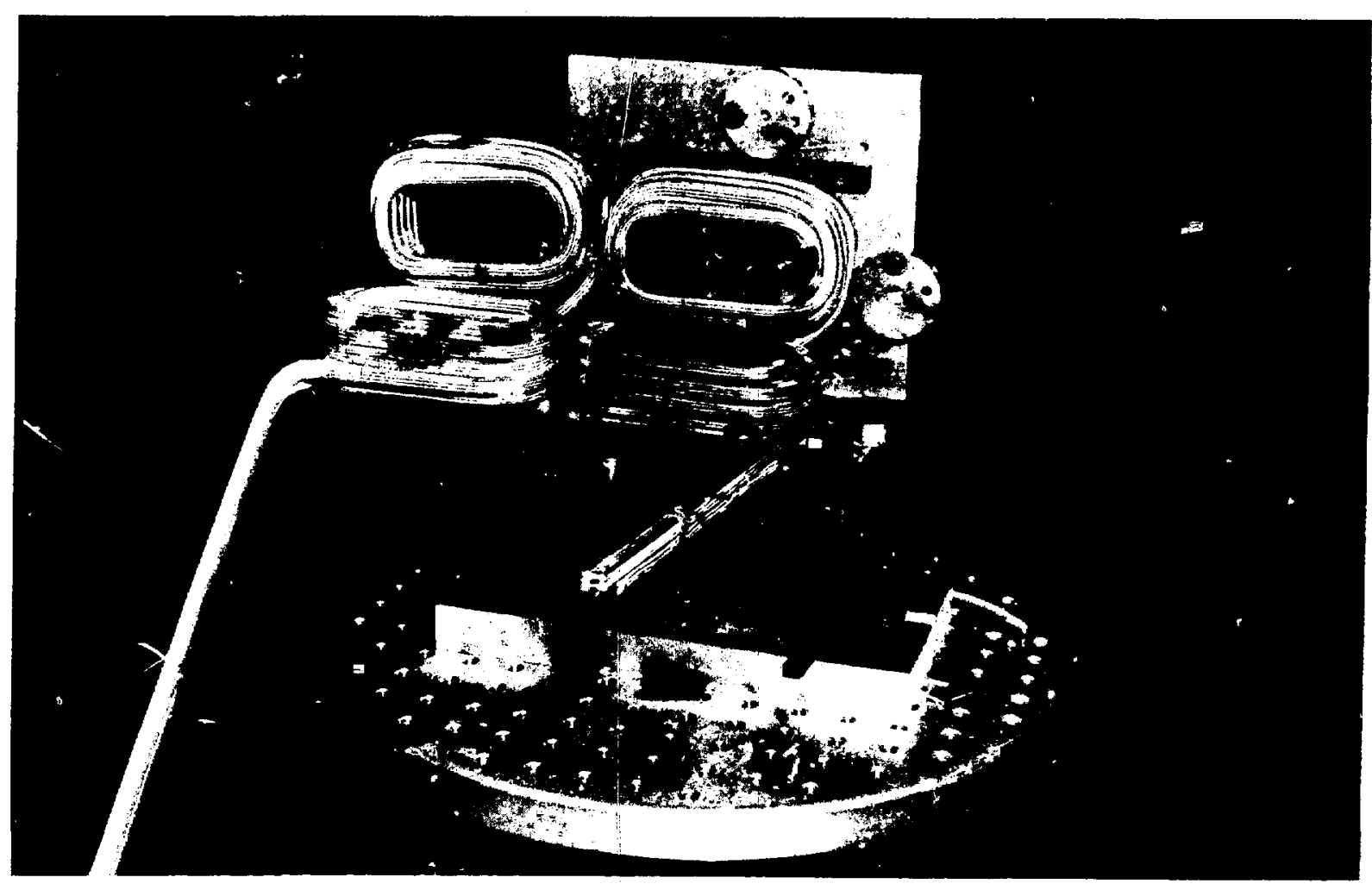

Fig. 14.

Quad coll winding (finish). 


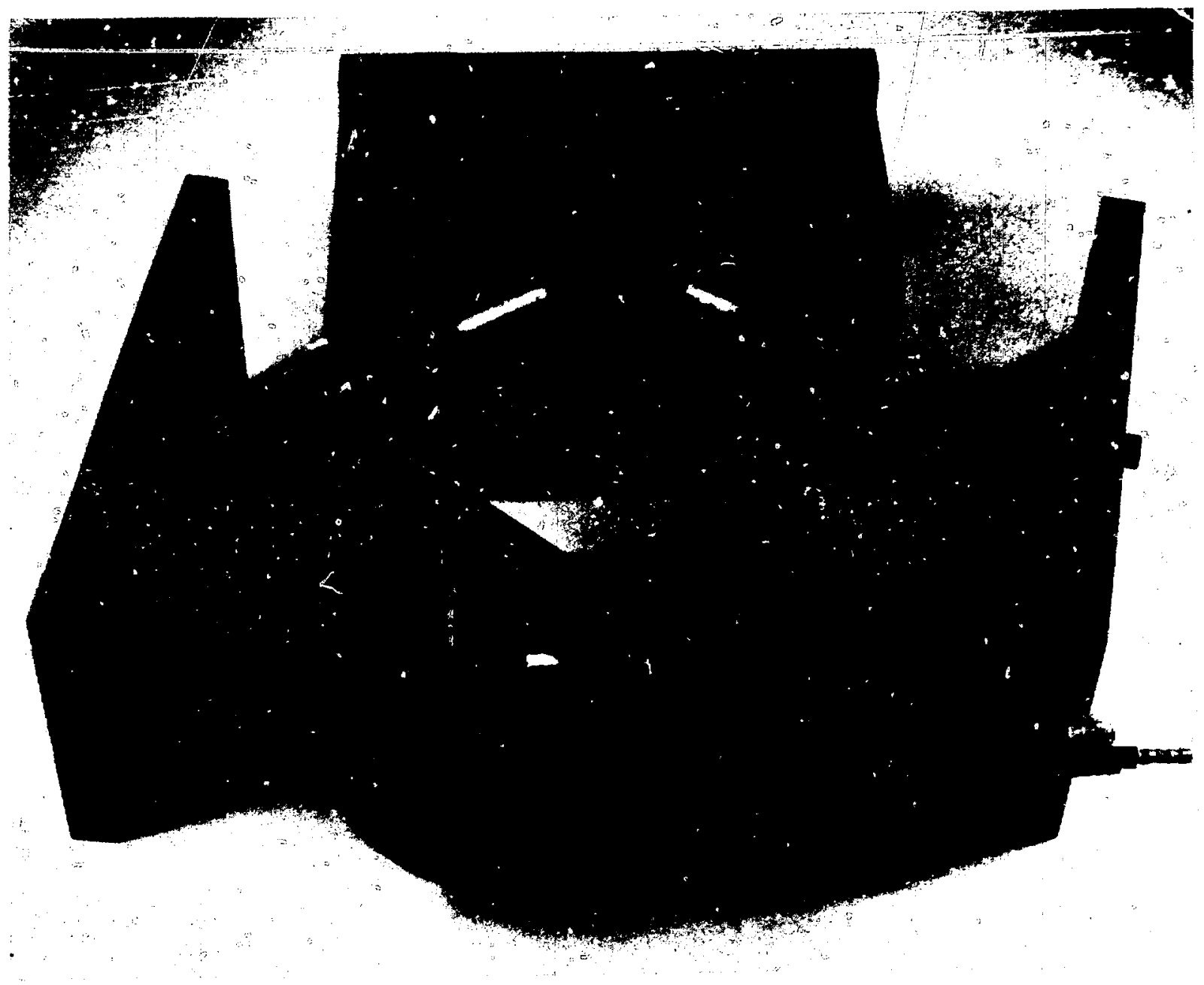

Fig. 15.

Quad potted coll and mold. 


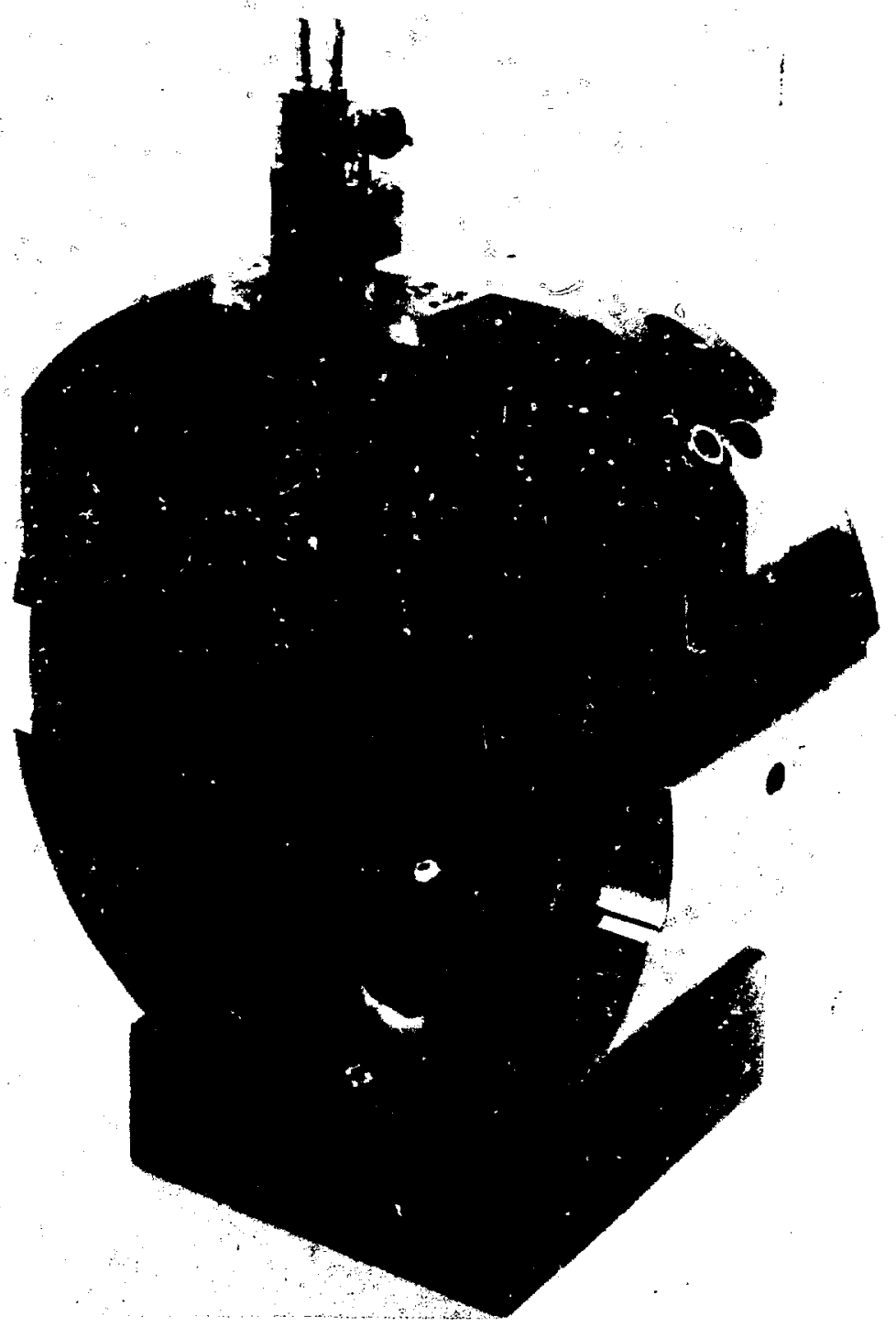

Fig. 16.

Quadrupole magnet. 
TABLE IV

MAXIMUM DEVIATION OF THE FOURTEEN QUAD

MAGNET HARMONIC MEASUREMENTS

$\begin{array}{rll}\frac{N}{2} & \frac{\text { TROM3 } \% \mathrm{~N}=2}{100} & \frac{\text { TROM8 } \% \mathrm{~N}=2}{100} \\ 3 & 0.032 & 0.069 \\ 4 & 0.072 & 0.085 \\ 5 & 0.11 & 0.087 \\ 6 & 1.2 & 0.96 \\ 7 & 0.10 & 0.034 \\ 8 & 0.083 & 0.044 \\ 9 & 0.051 & 0.015 \\ 10 & 0.56 & 0.55 \\ 14 & 1.2 & 1.2\end{array}$

TABLE V

QUADRUPOLE MAGNET PARAMETERS

$\begin{array}{lcl}\text { Bore } & 52 & (\mathrm{~mm}) \\ \text { Gradient } & 2.74 & (\mathrm{kG} / \mathrm{cm}) \\ \text { SG॰dl } & 32.74 & (\mathrm{kG}) \\ \text { Pole length } & 100 & (\mathrm{~mm}) \\ \text { Effective length } & 120 & (\mathrm{~mm}) \\ \text { Amp-turn/pole } & 7200 & (\mathrm{NI} / \mathrm{pole}) \\ \text { Current } & 900 & (\mathrm{~A}) \\ \text { Current density } & 22.1 & \left(\mathrm{~A} / \mathrm{mm}^{2}\right) \\ \text { Voltage } & 4.7 & (\mathrm{~V}) \\ \text { Power } & 4.23 & (\mathrm{~kW}) \\ \text { Water f1ow } & 120 & (\mathrm{~cm} / \mathrm{s}) \\ \text { Pressure drop } & 480 & (\mathrm{kPa}) \\ \text { Temperature rise } & 8 & \left({ }^{\circ} \mathrm{C}\right) \\ \text { Welght } & 40 & (\mathrm{~kg})\end{array}$


E. Steering Magnets

Originally, combined vertical and horizontal steering magnets vere considered for the new TR because of the space limftations. The transverse field uniformlty and space constraints dictated the use of dipole magnets. At this point the approximate locations of the steering magnets were established. Several beam-transport tunes for the long and the short path were studied to determine the maximum $\rho B \cdot d 1$ required. The design bending strength was defined to be $50 \%$ greater than the maximum requirement. The magnet gap was the clear aperture, plus two times the beam pipe thickness, plus alignment clearance. With an $\delta B \cdot d 1 \approx 30 \mathrm{kG} \cdot \mathrm{cm}$ and a gap of $5.40 \mathrm{~cm}$, the TR-II steering magnets are more in the nature of small water-cooled bending nagnets than conventional steering magnets.

Again, POISSON was used to design the core and coil geometry. The pole length is small compared with the gap; consequently, most of the field is in the fringe. For this reason, and the fact that fourteen (twelve units installed plus two spares) steering magnets were to be constructed, it was necessary to perform extensive measurements on a prototype. All steering magnets are identical. Vertical and horizontal steering are achieved by rotating the magnet $90^{\circ}$.

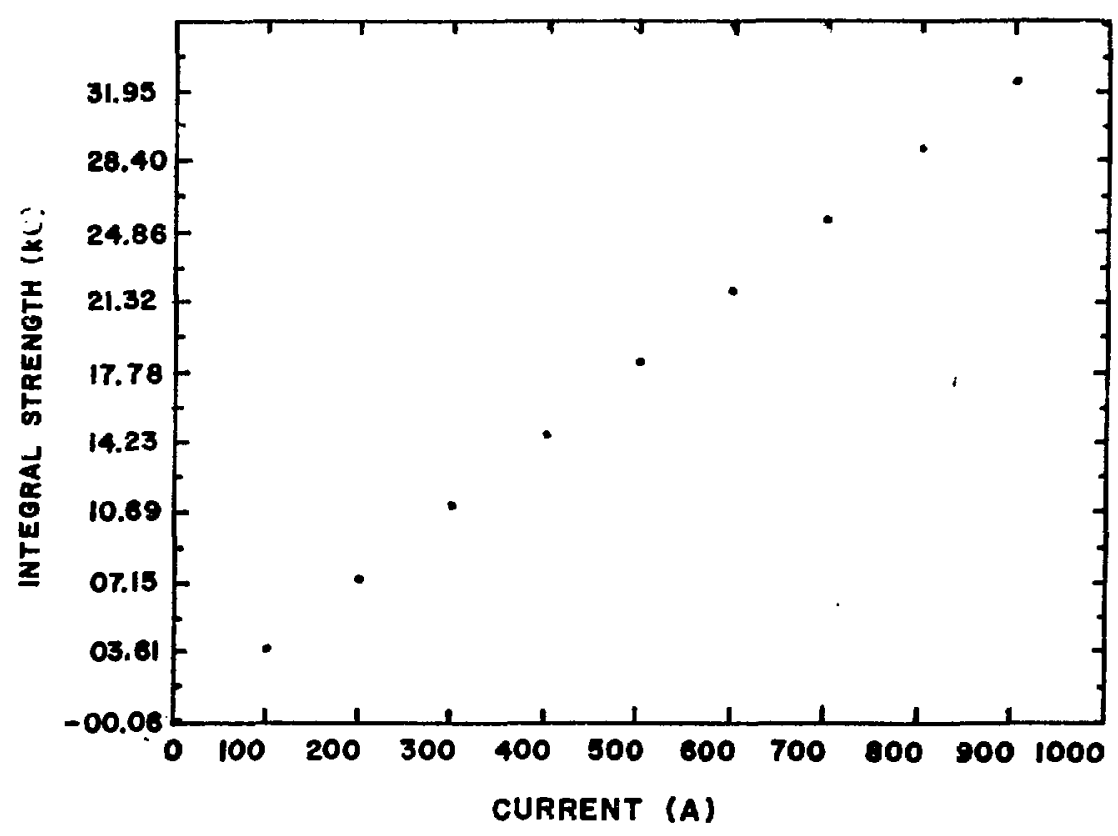

Fig. 17.

Quad SG.dl vs I. 
The steering magnets are sma.11 "H" magnets with coils wound with $4.72-\mathrm{mm}$ square by 3.18-mm Inside-diameter hollow copper conductor. After construction of the prototype steering magnet, very 1ittle work was required to prepare the winding form and casting mold for production. Some of the construction phases are shown in Figs. 18 and 19.

Typical characteristics of the new TR-II steering magnets are shown in Table VI.

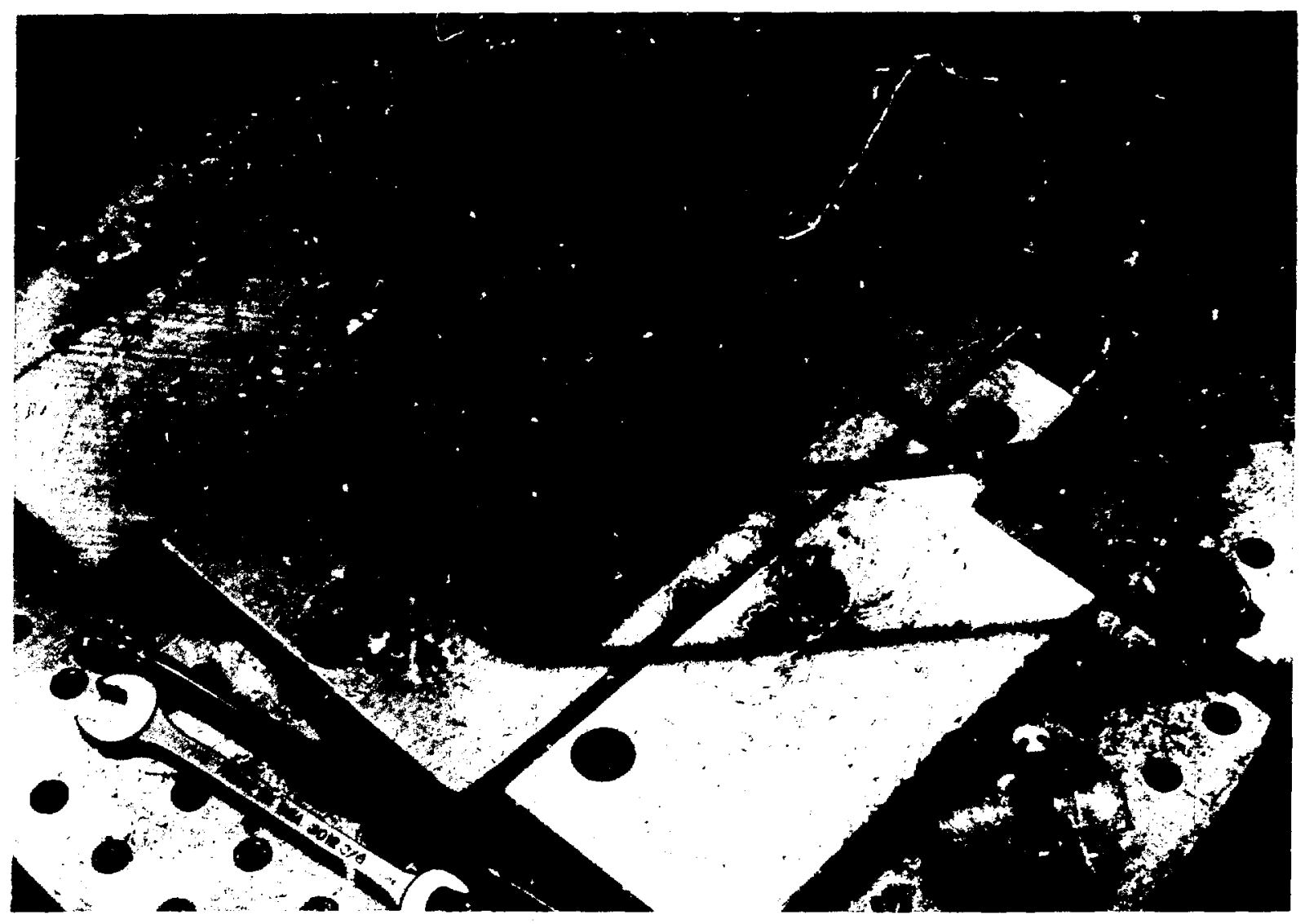

Fig. 18.

Steering-magnet coil winding. 


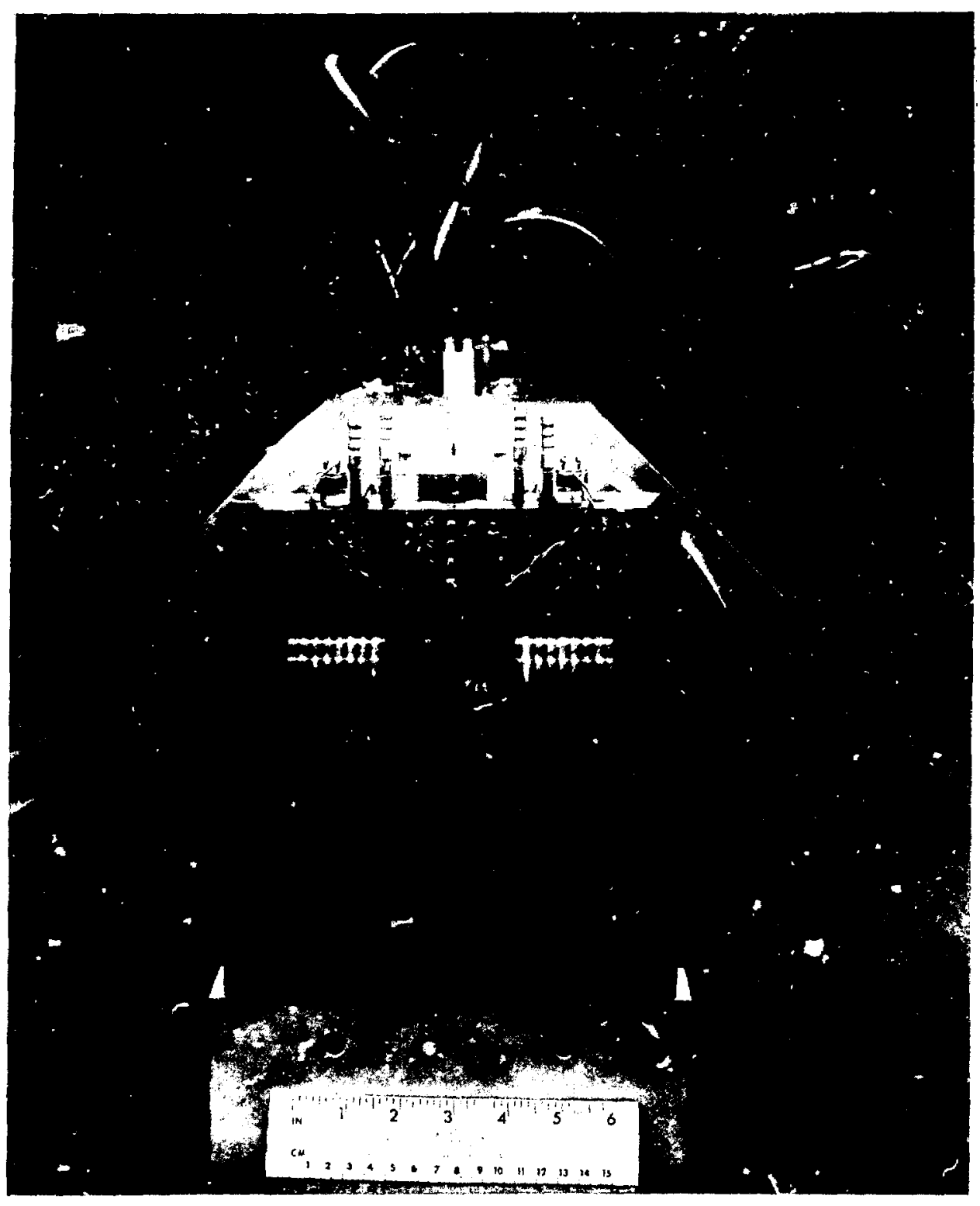

F1g. 19.

Steering magnet.

F. TR-II Magnet Alignment Mounts

The beam-transport deslgn for TR-II requires a very large number of components to be positioned in a confined space (shown schematically in Fig. 2) and in the beam channel (FIg - 20). The tradftional approach of Individual adjustable mounts for each component was not practical for this close-packed 
condition. A mounting design was originated which grouped the components on a common base. This saddle base was machined to hold quads, steering magnets, and beam boxes in precise $\pm 0.05-\mathrm{mm}$ fixed alignment relative to each other. Magnets and beam boxes were positioned on the saddles to this accuracy using shoulder screws. The complete saddle, shown In F1g. 21, was mounted so that an entire group of components could be aligned to beam line. The bending magnets were mounted on standard three-point supports. A unique feature of the bender support system and magnet design, shown also In Fig. 21, allows the magnets to be removed without breaking the vacuum envelope (accomplished by removing the top half of the magnet and lowering the bottom half until the beam pipe is clear of iron and colls). This section is then moved transversely until it is out from under the beam pipe. The quad and steering magnets can also be disassembled for removal.

TABLE VI

STEERING-MAGNET PARAMETERS

$\begin{array}{lcl}\text { Gap } & 54 & (\mathrm{~mm}) \\ \text { Width } & 97 & (\mathrm{~mm}) \\ \text { Fleld } & 2.9 & (\mathrm{kG}) \\ \text { JB.dL } & 27 & (\mathrm{kG} \cdot \mathrm{cm}) \\ \text { Pole length } & 44.5 & (\mathrm{~mm}) \\ \text { Effective length } & 85 & (\mathrm{~mm}) \\ \text { Amp.turns } & 15,000 & (\mathrm{NI}) \\ \text { Current } & 250 & (\mathrm{~A}) \\ \text { Current density } & 18.6 & \mathrm{~A} / \mathrm{mm}{ }^{2} \\ \text { Voltage } & 7.5 & (\mathrm{~V}) \\ \text { Power } & 1.9 & (\mathrm{~kW}) \\ \text { Water flow } & 44 & (\mathrm{~cm} / \mathrm{s}) \\ \text { Pressure drop } & 550 & (\mathrm{kPa}) \\ \text { Temperature rise } & 10 & \left({ }^{\circ} \mathrm{C}\right) \\ \text { Weight } & 9 & (\mathrm{~kg})\end{array}$




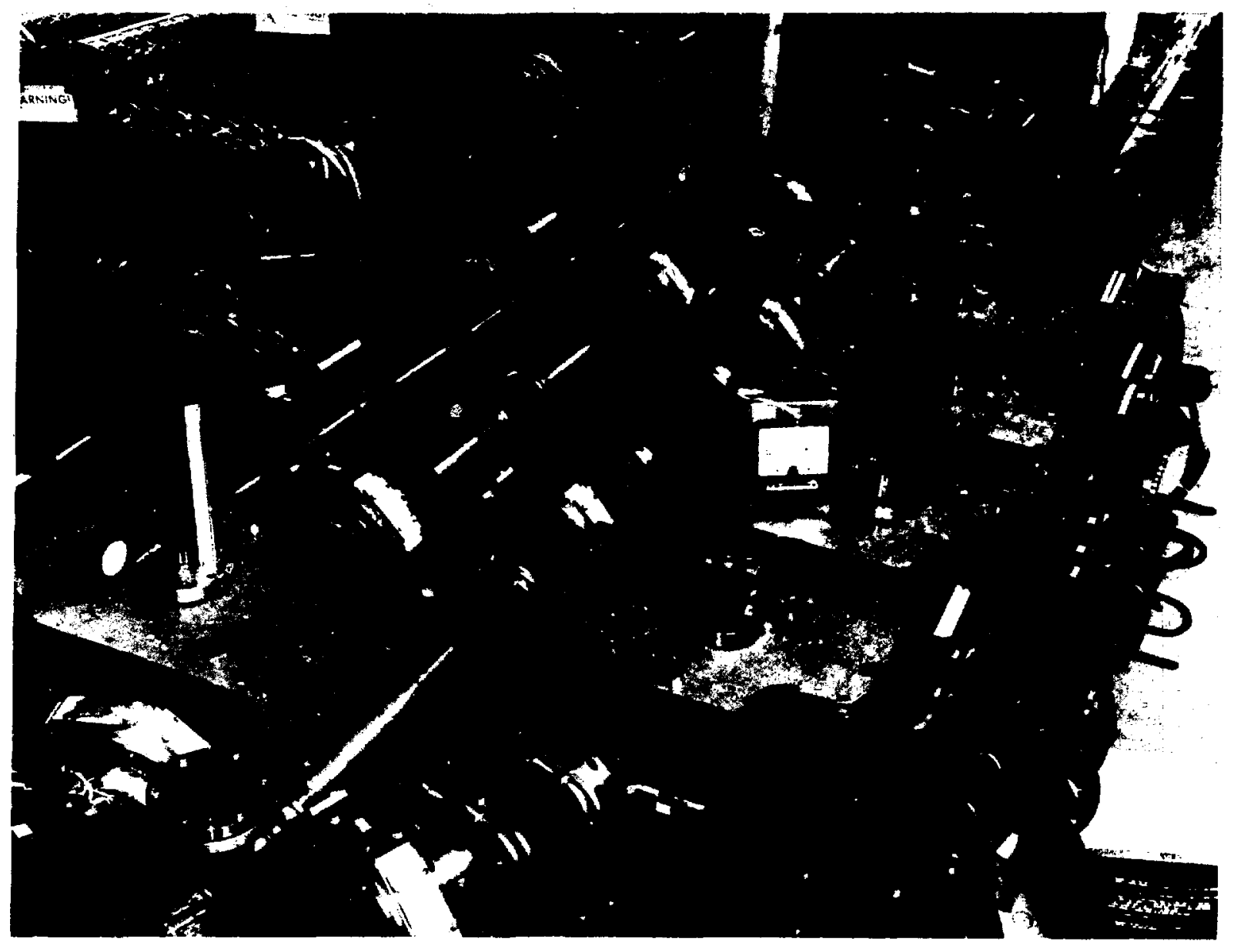

Fig. 20.

TR-II "dense pack" beam transports.

G. TR-II Alignment

Initial tolerances requested for the location of TR-II components were very tight (on the order of $\pm 0.05 \mathrm{~mm}$ ). A quick analysis indicated that $1 \mathrm{f}$ all components were machined to the smallest practical limit, an overall best effort would be in the $( \pm 0.08 \mathrm{~mm})$ range for component location. This error is the accumulation of tolerances for the magnet tooling hole location $( \pm 0.03 \mathrm{~mm})$, fixture fabrication $( \pm 0.01 \mathrm{~mm})$ and optical tooling 1 imits of $6.1 \mathrm{~m} / 200,000$ 


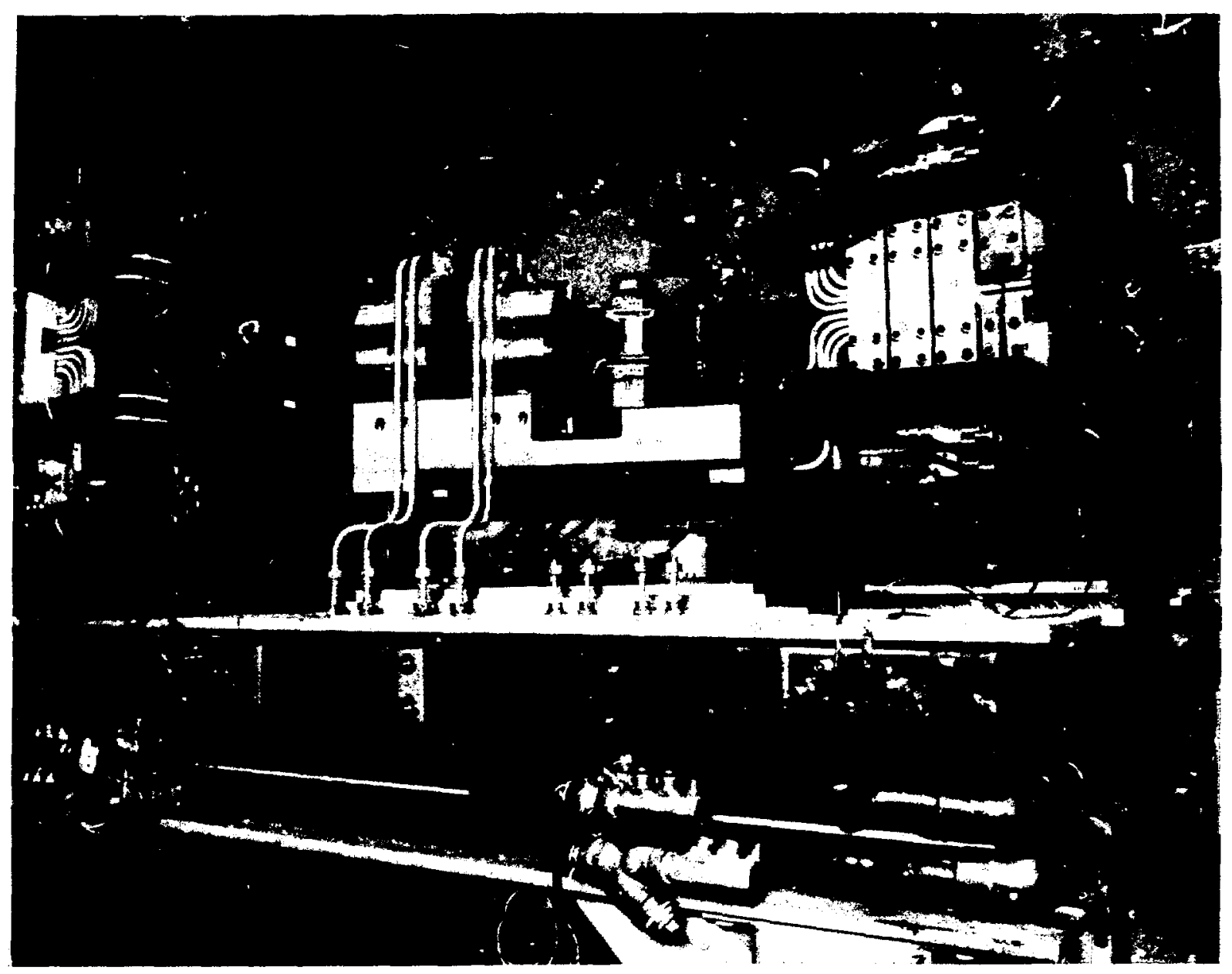

Fig. 21 .

Magnet alignment mounts.

$( \pm 0.03 \mathrm{~mm})$. This type of precision ruled out the normal method of TR alignment using portable instrument stands for alignment scopes and hand-held tooling scales referenced to an offset line. Two completely different systems were studied as solutions to this critical alignment task.

Our first proposal was to install a permanent two-bar tooling dock in the Transition Region. This would require a horizontal $x$-bar mounted above module 5 and a z-bar located along the south wall of the beam channel. These tooling bars would function as a standard tooling dock and give optimum results due to rigid instrument-mounting and self-checking features of a tooling dock. This 
system would require dedicated equipment to stay in the beam channel and it would also take up valuable space.

The other system considered was a three-dimensional measuring system based on two digital theodolites interfacing with a desktop computer - this new technology was available from two companies. The two systems were demonstrated at Los Alamos and had hands $n$ evaluation by our alignment technicians. It was soon Evident that the computer-aided alignment systems were capable of $\pm 0.08-$ $0.13-\mathrm{mm}$ precision in three-dimensional setups and had the features to be very versatile. This system's performance was sufficiently impressive that a decision was made to purchase one for the IR-II alignment and for other projects in the future.

The alignment system, a K\&E "AIMS" shown in use at TR-II in Fig. 22, wi11 be discussed in detall later in the report. Some development was necessary to make targets that were best suited for three-dimensional measuring; a cone-shaped target was chosen as the best for all-direction viewing. Three members of the alignment section were sent to the vendor's plant for training in the system's use and applications. The alignment crew also practiced using the system on magnets at the TR-II staging area in the Equipment Test Lab (ETL).

A11 TR-II beam line components requiring optical alignment were processed through the ETL tooling dock. This procedure involved precise mechanical measurements and the mounting of alignment target pads on the magnets. Quadrupole magnets, steering magnets, and beam boxes were checked for relative alignment when mounted in their common cradle.

Initial alignment of the magnets on their alignment mounts was done at the ETL staging area. Alignment of actual beam line parts on the support structure was done to $\sim \pm 1.5 \mathrm{~mm}$. Rough alignment allowed precise placement of water and power leads to the magnets, which helped to assure that parts would fit during installation in the beam channel.

The Analytical Industrial Measuring System (AIMS) is a new alignment system developed by the Keuffel and Esser Co. It consists of two digital electronic theodolites, a controller/computer, a printer, and a cart assembly (see Fig. 22). The theodolites have LED digital readout with angular resolution of 9 $\times 10^{-4}$ degree. The controller is a microcomputer with dual diskette drives, video display screen, and keyboard. The system's software package has the capability of doing several different measurement routines (see Appendix $B$ ). Angles from the theodolites are electronically entered into the computer, which 


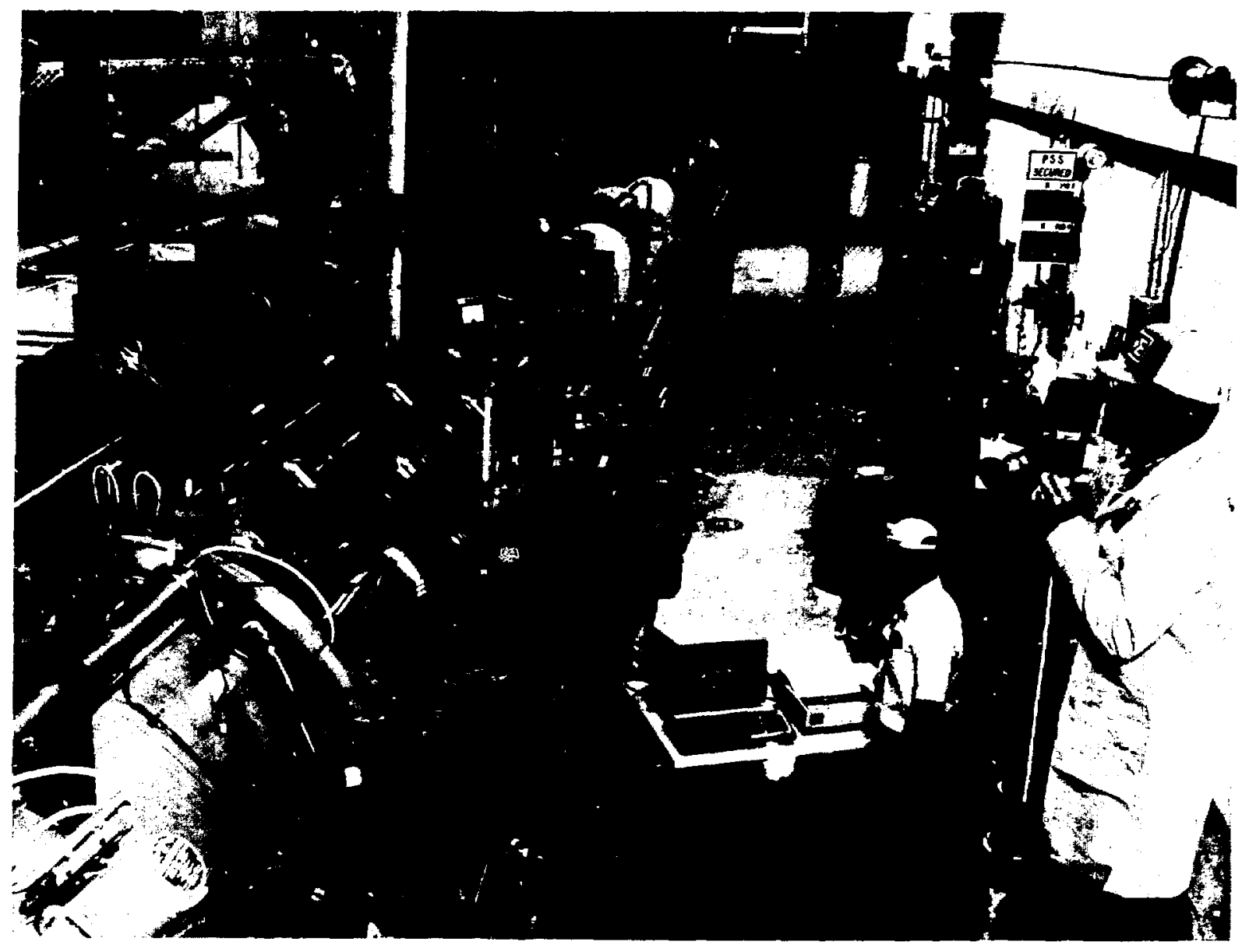

F1g. 22 .

Keuffel and Esser Analytical Industrial Measuring System, (AIMS).

then performs the three-dimensional vector arithmetic and prints the output. A typical working printout is shown in Fig. 23. Data printed for each target station are the following:

1. target number and comment if desired;

2. azimuth anci elevation angles for each theodolite; and

3. trlangle apex angle, formed by theodolites and target; this can be used as a figure of merit in determining measurement accuracy. 4. XYZ coordinates and error from theoretical coordinates. 
THURS. $5 / 12 / 83 \quad 1: 00 \mathrm{PM}$

RESTART AFTER LUNCH, COMPLETE SET OF DATA FOLLOWS

ANALYTICAL INDUSTRIAL METROLOGY SYSTEM,

WITH KEE DIGITAL THEODOLITES... JOB 1

DIRECT DIGITAL THEODOLITE Nbr 1 AZIMUTH $=0.0000$ ELEVATION $=83.4440$ DEGREES

DIRECT DIGITAL THEODOLITE Nbr 2 AZIMUTH $=0.0000$ ELEVATION $=82.9032$ DEGREES ABOVE WERE AZIMUTH ZERO REF READINGS

AUTOMATIC MODE

THEODOLITE OBLIQUE SEPARATION= 157.535 SYSTEM RESTART WITH UNDISTURBED SETUP

$101 \mathrm{BM}-1$ UP

DIRECT DIGITAL THEODOLITE Nbr 1 AZIMUTH=329.9904 ELEVATION=106.6145 DEGREES

DIRECT DIGITAL THEODOLITE Nbr 2 AZIMUTH $=320.4549$ ELEVATION $=97.3581$ DEGREES MEASUREMENT TRIANGLES APEX $=58.143$ DEGS.

$U C x=-.0000 \quad U C y=-.0002 \quad U C_{z}=-.0007$ INCH, ARE COMPONENTS IN XYZ DIRECTIONS.

$79 X=14.3904$ INCHES. $\quad Y=-0.0050$ INCHES. $\quad Z=10.0784$ FOR TARGET 101

$X E R R=+0.0044$ INCH. $\quad$ YERR $=-0.0050 \mathrm{INCH} . \quad$ ZERR $=+0.2714$ FROM NOMINAL

UNCERTAINTY ANGLE $=0.0002$ DEGREES, EQUAL TO -0.007 INCH + OR - FROM MEAN.

$L=83.173$ AND $R=184.706$ RANGES FROM THEODOLITES TO TARGET.

400 TARGET

HAVE RE-ZEROED COORDINATE SYSTEM

DIRECT DIGITAL THEODOLITE NBR 1 AZIMUTH=316.0935 ELEVATION=97.0336 DEGREES

DIRECT DIGITAL THEODOLITE NBR 2 AZIMUTH $=317.9781$ ELEVATION $=92.9130$ DEGREES MEASUREMENT TRIANGLES APEX $=47.439$ DEGS.

$U C_{x}=0.0000 \quad U C y=0.0002 \quad U C_{z}=0.0014$ INCH, ARE COMPONENTS IN XYZ DIRECTIONS.

$80 X=-27.8976$ INCHES. $Y=79.4326$ INCHES. $Z=-10.3886$ FOR TARGET 400

XERR $=-21.9666$ INCH. YERR $=+79.4326 \mathrm{INCH} . \quad$ ZERR $=-33.8596$ FROM NOMINAL

UNCERTAINTY ANGLE $=0.0004$ DEGREES, EQUAL TO 0.0014 INCH + OR - FROM MEAN.

$L=84.828$ AND $R=201.990$ RANGES FROM THEODOLITES TO TARGET .

Fig. 23 .

AIMS real-time printout of alignment data.

5. uncertainty angle -- mis-aim error of lines of sight and the equivalent distance in inches.

6. distance between last two targets.

A TR-II coordinate system reference was established by target \#400 on the 201-MHz tank and target $\# 500$ on the $805-\mathrm{MHz}$ module 5, as shown in Figs. 24 and 25. These two monuments were the master targets used to position all components in the TR-II. 


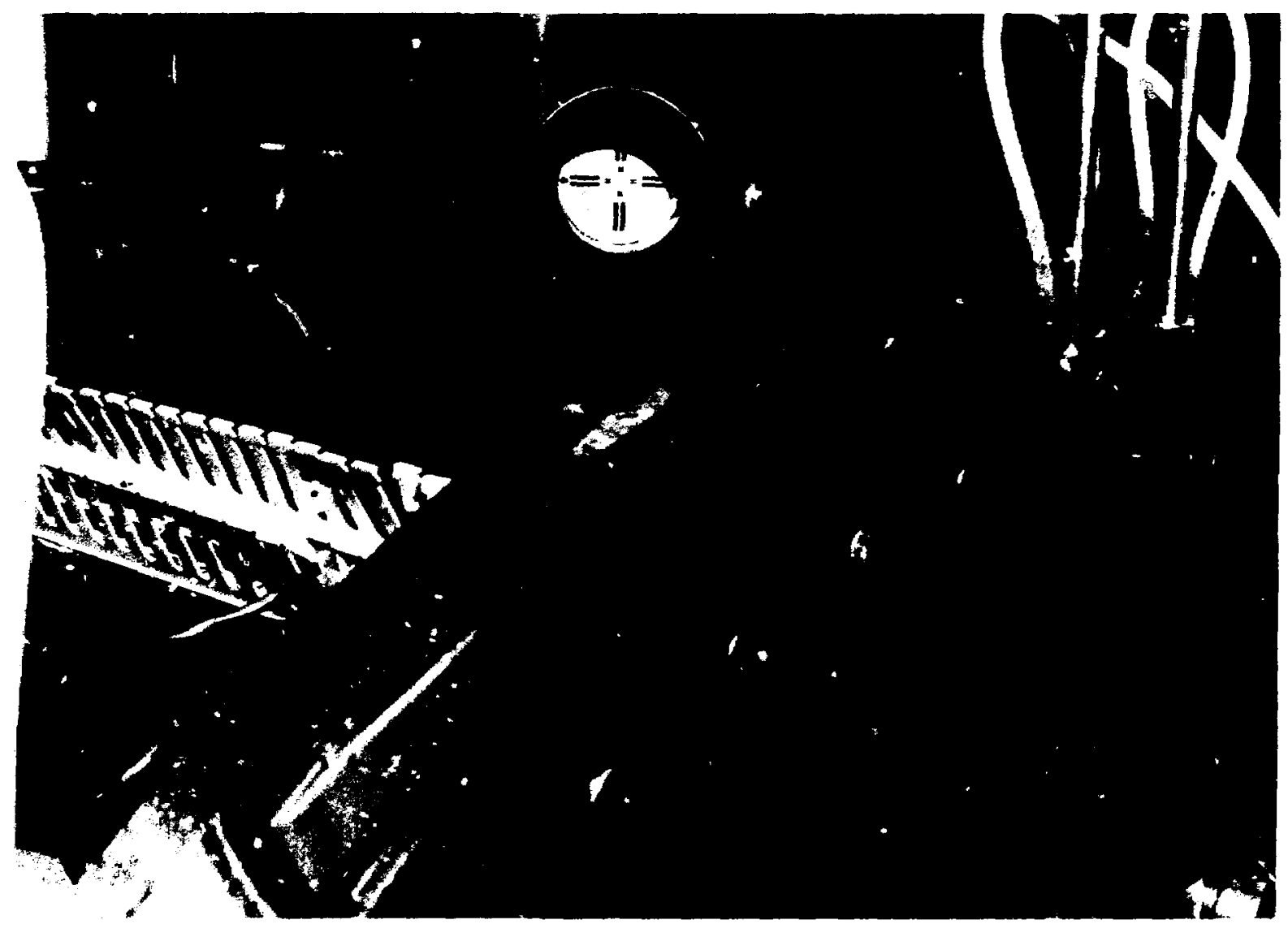

Fig. 24.

Target station \#400 201-MHz tank 4 .

The procedures for using the AIMS are detalled in the following steps:

1. Electronically level each theodolite.

2. Establish a common baseline between the two instruments by pointing at each other in the direct and reverse sighting modes. This is recorded in the computer.

3. Set zero reference azimuth angles for each instrument by sighting on a common target and recording.

4. Set system scaling factor by sighting and recording two target positions on a known gauge bar, as shown in Fig. 20.

5. Sight on master targets $\$ 400$ and $\# 500$ and transfer coordinate system orlgin from theodolite \#1 to the master targets. 


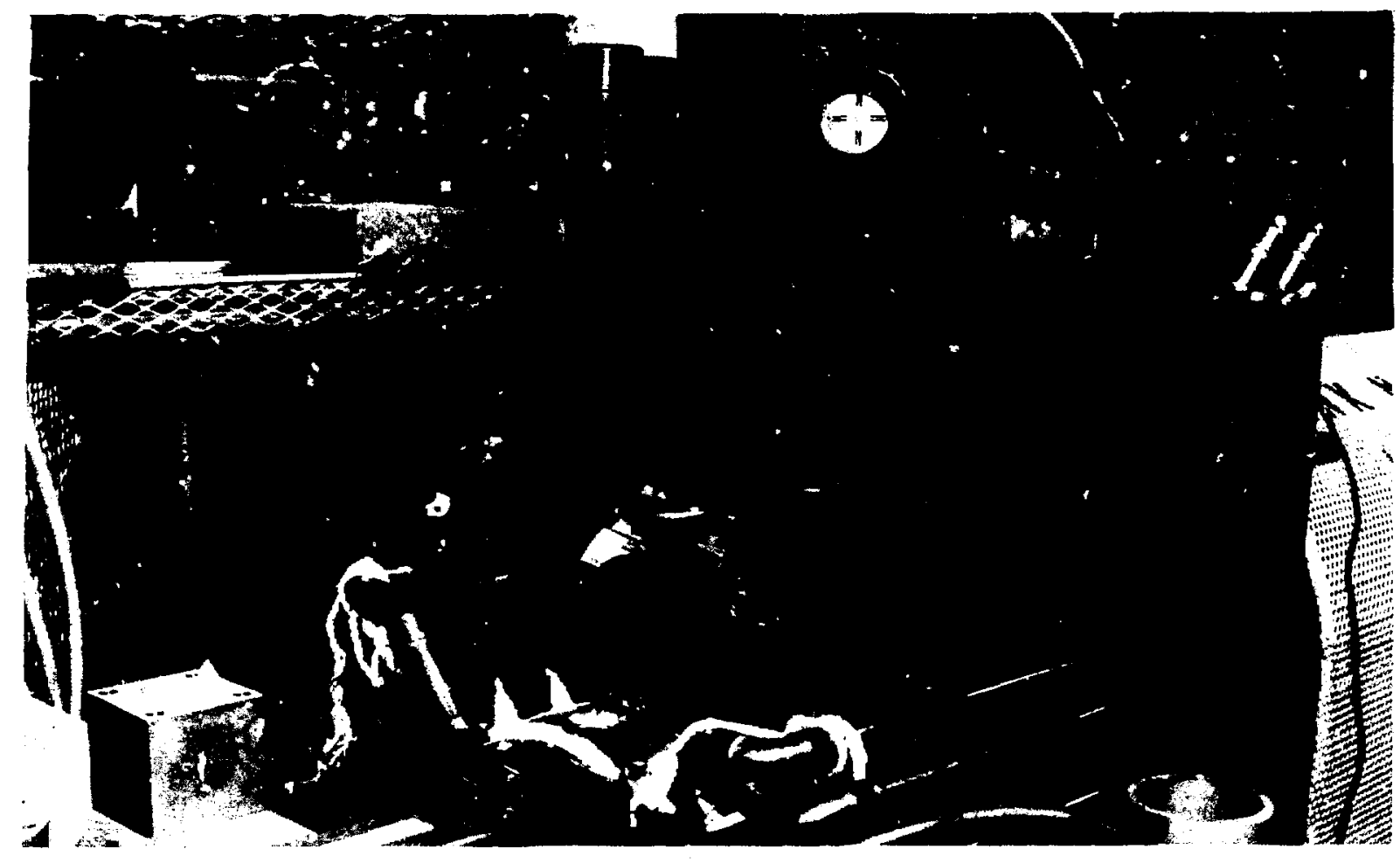

F1g. 25.

Target station $\left.\right|^{500} 805-\mathrm{MHz}$ module 5 .

6. Component targets can then be sighted for alignment measurements. A theoretical $X, Y$, and $Z$ coordinate position for each target on every magnet was entered into the computer. As the measured data are entered, they are automatically compared to the theoretical position and the difference is printed out as $X, Y$, and $Z$ exrors. A recapitulation of coordinate data with errors is shown In Appendix $C$.

The AIMS was not used to set elevation, as evidenced by the large $Z$ errors shown in Fig. 23 and Appendix C. A Zeiss level, shown in Fig. 26, was used with tooling scales to make direct elevation readings from the magnet-alignment pads. The AIMS can make exact elevation measurements, but the target elevation must be referenced exactly to its seating shoulder in the tooling hole. For a clear line of sight, it was occasionally necessary to move a target vertically, thus destroying the target's elevation reference. The optical level can accommodate offsets without extra measurements or calibrations. The AIMS $X, Y$, and $Z$ axes identification is equal to the $X, Z$, and $Y$ axes on the accelerator. 


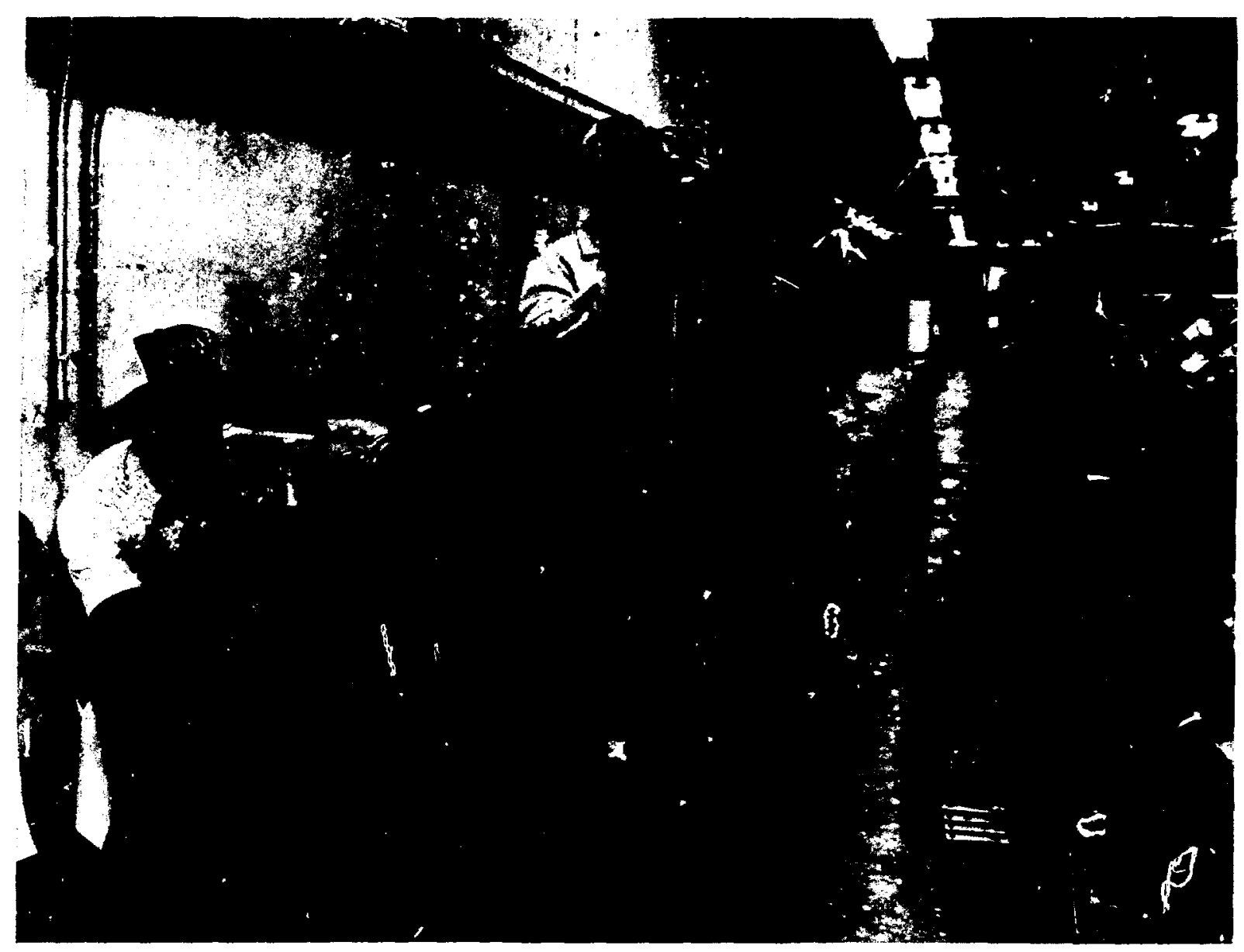

Fig. 26.

TR-II elevation reading with a Zeiss level.

The complete TR-II alignment process was performed twice in the beam channel. The preliminary alignment was done to $\pm 0.25-\mathrm{mm}-0.38-\mathrm{mm}$ prior to the Installation of water, electrical, and vacuum services. Final allgnment to $\pm 0.12-m$ or better was done after all installation was complete, except for beam box actuators.

\section{H. TR-II Support Structure}

The TR-II support structure was designed to satisfy a variety of requirements. The primary conditions were that (1) structural design be done to minimize deflection, (2) utility lines be integrated with structure members where possible, (3) underside of support be clear for vacuum pump mounting and personnel access, (4) rigidity of structure be adequate to allow movement of 
loaded support assembiy without damage to components or utility lines, (5) standard structural shapes with welded joints be used for economy and to provide a rigid frame, and (6) one frame rail have a removable section to allow for future bucket rotator installation.

The basic structure was fabricated from wide-flange steel beams and square structural tubing, as shown in Fig. 27. Lateral braces are positioned at $45^{\circ}$ to provide maximum torsional stiffness. Heavy components are located over major structure members as shown by base plate locations in Fig. 28. Calculations indicate that this structure w111 have a maximum deflection of $\sim 0.8 \mathrm{~mm}$ under a full load of $9000 \mathrm{~kg}$.

The structure has notches and holes cut at proper locations, as shown in Fig. 27, to allow close packed routing of utility lines. These include a 50-mm square copper bus for magnet power, cooling-water manifolds, and copper lines for bus-to-magnet jumper leads.

\section{TR-II Vacuum System}

The TR-II vacuum system has been designed as an integrated system in order to correct: some previous problems of poor pump-down time and maintenance access. The prime design considerations were fast pump-down time and maintenance of high conductance in the vacuum 11 nes. These requirements are especially important in the TR because fast turnaround times are necessary for repairs to minimize downtime.

A layout of the vacuum system is shown in Fig. 29. The 51-mm-diameter beam pipes follow three beam paths through the TR-II. Triangular vacuum chambers are positioned in BM-01 and -04. A 153-mm-diameter manifold runs lengthwise in the support structure connecting to the beam plpes, as shown in Fig. 29. This pipe has drop connections for three $500-\ell / s$ ion pumps, one cryopump, two roughing ports, and one auxiliary port.

The close-packed spacing of the magnets and beam boxes did not allow room for the use of LAMPF standard flanges at most joints. Special joints and vacuum envelopes were designed so that rellable seals could be made in extremely restricted space. The joints between steering magnets and beam boxes utilized a split-ring flange with a Con-0-Ring type seal. The sealing disc is thin enough to allow limited bellows-like deflections. Bolt clearance is so tight that hex drive rods were assembled in place in the mounting cradles to allow removal of socket head screws. 


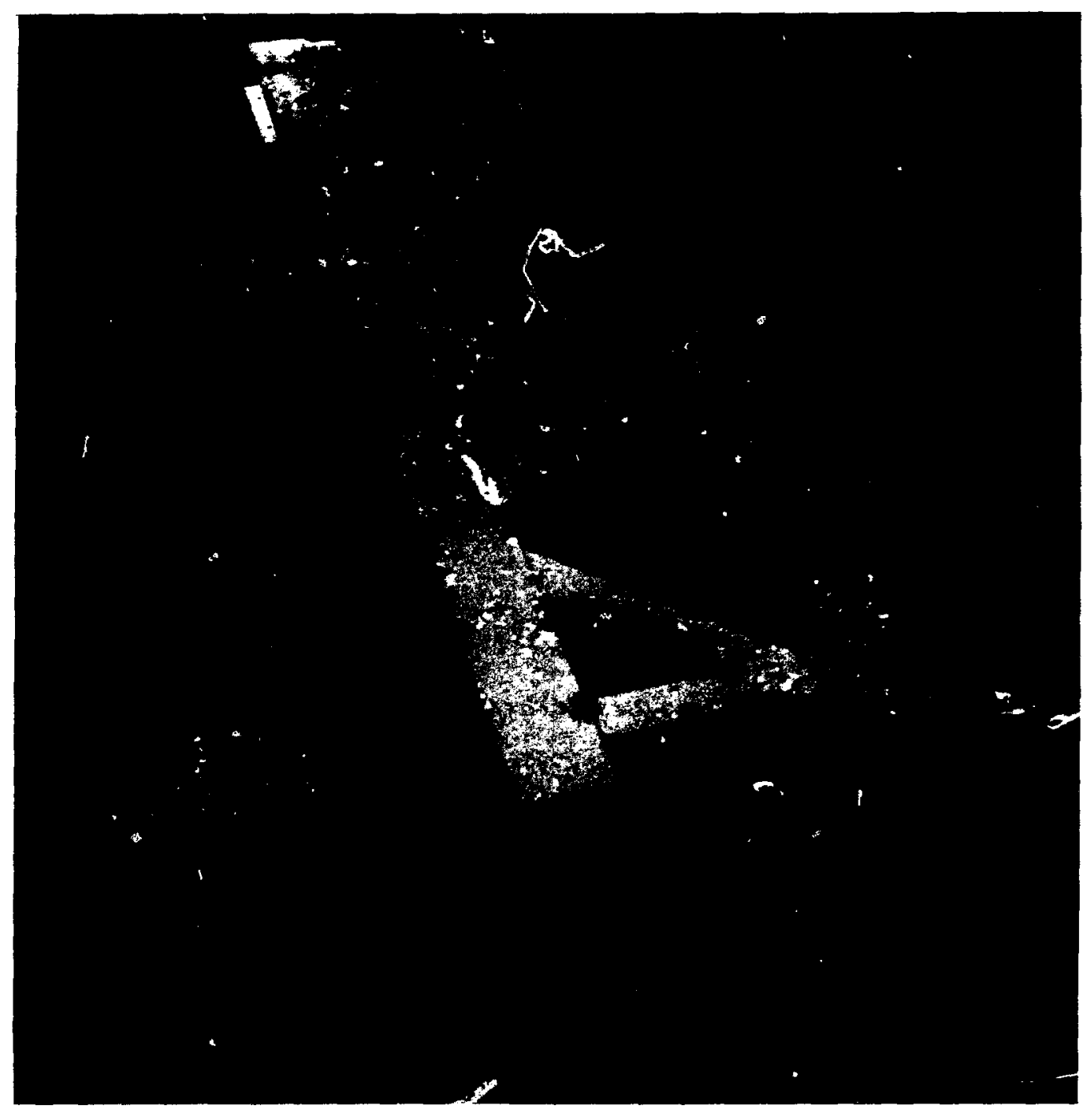

F18. 27.

TR-II support frame.

LImited spacing between $B M-05,-06,-07$, and -08 and a beam box between BM-06 and -07 dictated the need for a continuous beam envelope,without joints in this area. The resulting design, shown in Fig. 30, was nicknamed the "Albatross," for obvious reasons. This chamber was fabricated from 2.4-mm-thick stainless steel with the machined center section functioning as a beam box. 


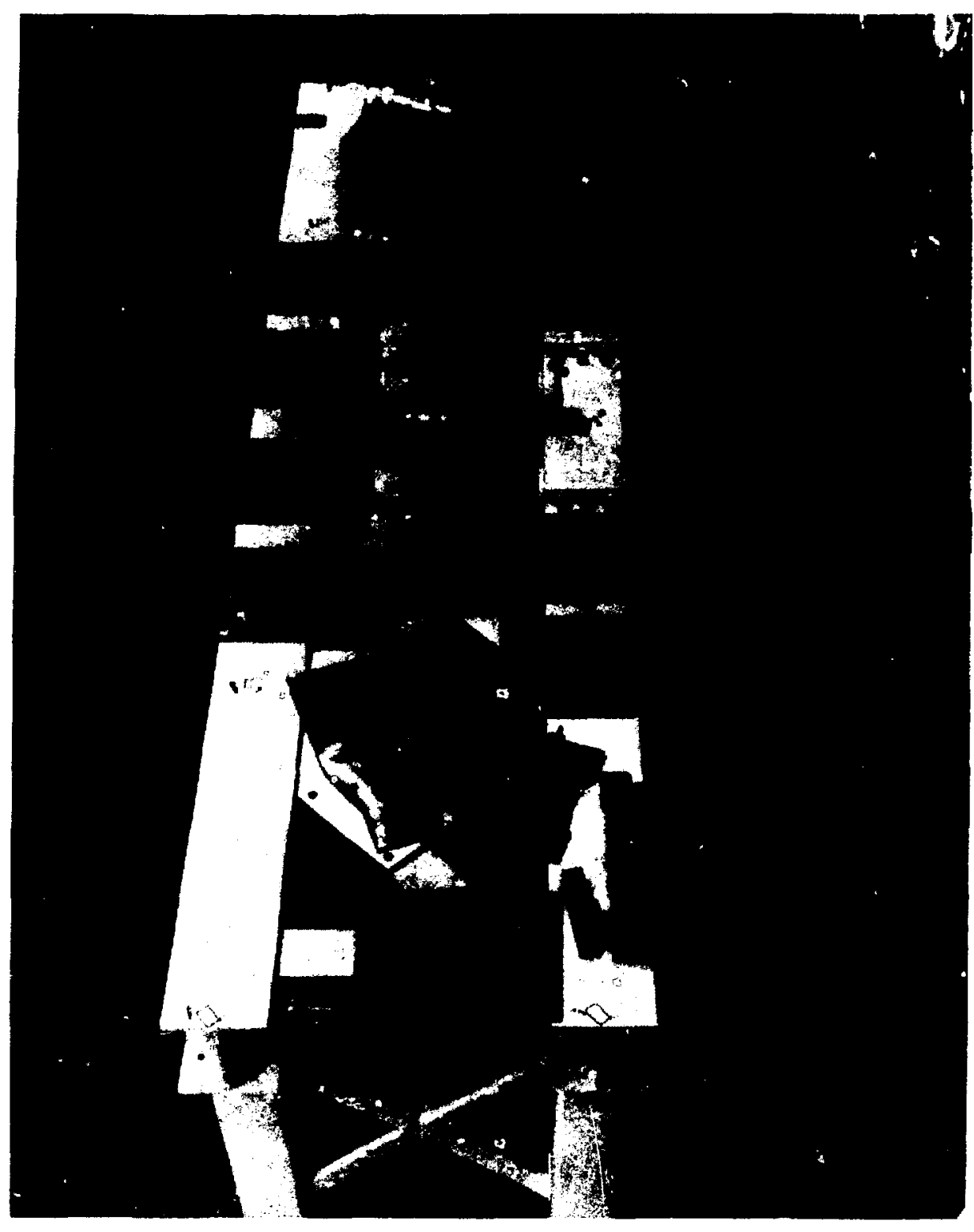

FIg. 28.

TR-II component base plates.

The BM-01 vacuum chamber also functions as a low-energy beam absorber. The absorber was made by adding Poco graphite and water cooling to the chamber wall exposed to the proton beam. The graphite was covered with $0.05-\mathrm{mm}$ titantum foil to hold it in place if breakage occurs. 


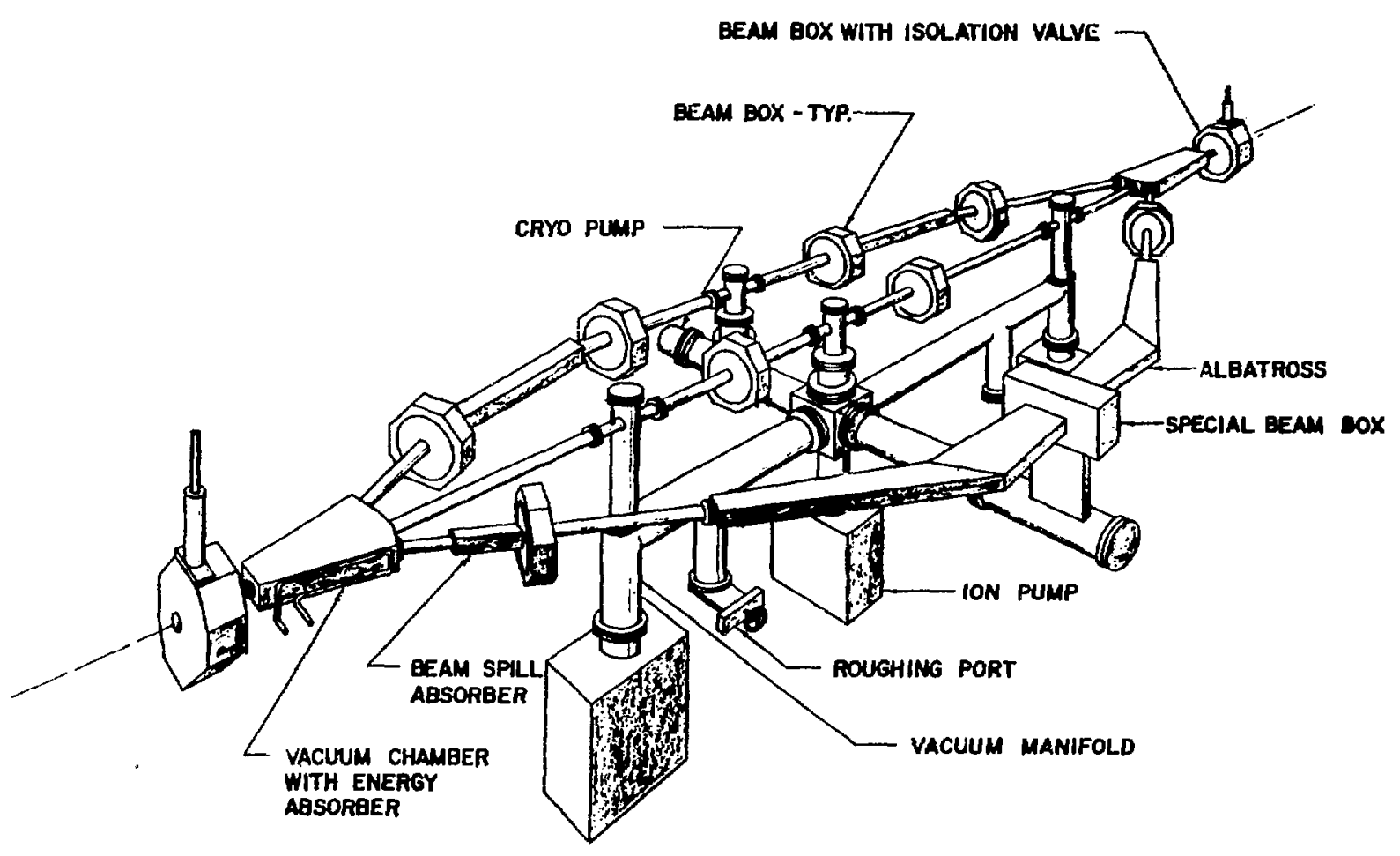

Fig. 29.

TR-II vacuum system.

Space limitations required custom-built vacuum isolation valves at each end of the TR-II, so the valves were designed integrally with the end beam boxes as shown In Fig. 31, Increasing their overall length by only $19 \mathrm{~mm}$. In the open position, the valve gate is offset approximately $2 \mathrm{~mm}$ from the sealing surface. When the valve is closed, the sealing force is provided by an air cylinder and the wedge action of mating inclined planes. The entire mounting system is flexible enough to permit the gate to move $2 \mathrm{~mm}$ sideways and remain parallel to the seallng surface.

Parameters of the TR-II vacuum system are given In Appendix D.

\section{J. TR-II Electric Power System}

The TR-II power system was designed jointly by MP-11 (power supplies) and MP-8 (bus bars and distribution). Power supply specifications are listed in Appendix E. Considerable attention was paid in routing magnet power to minimize 


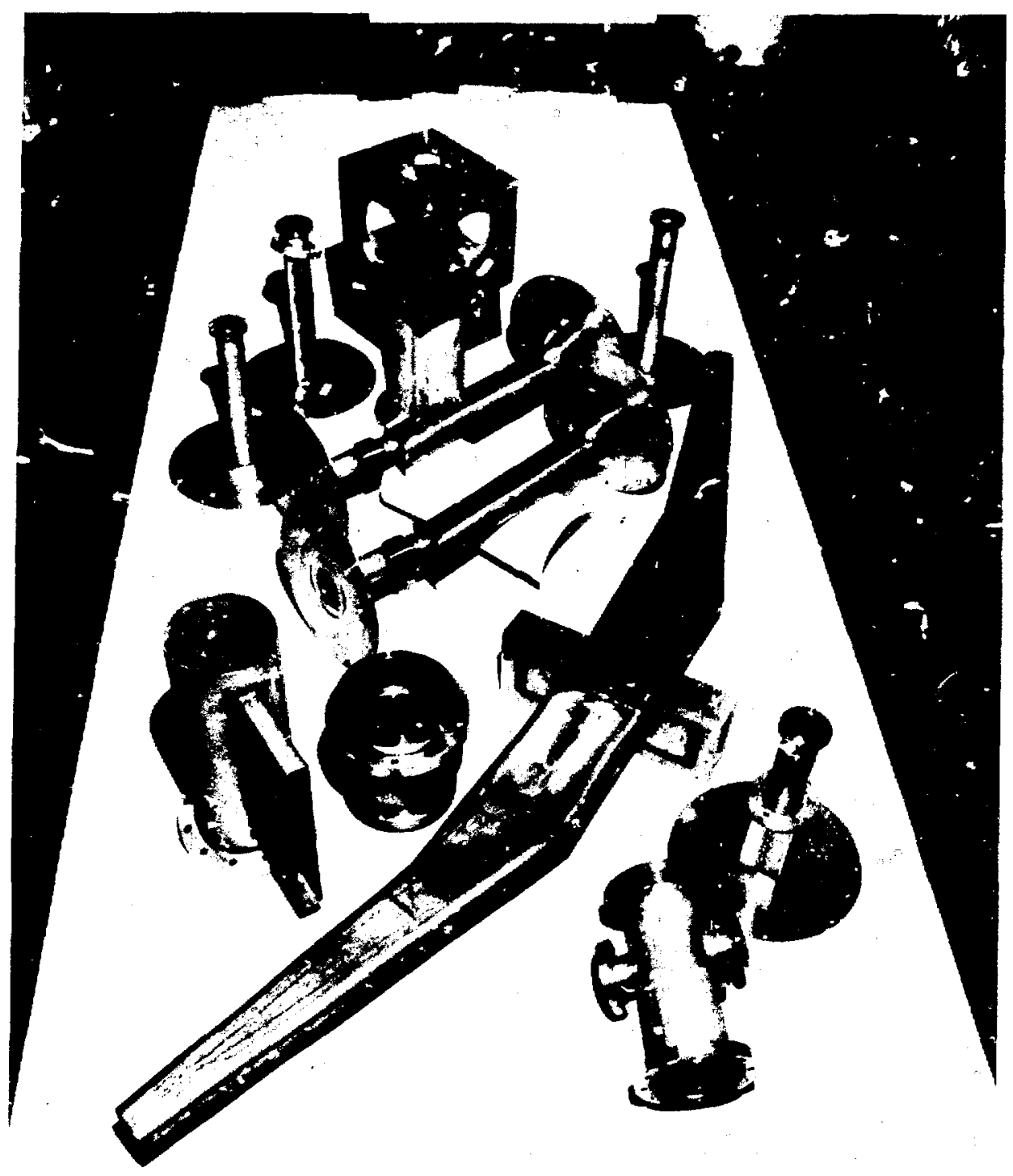

Fig. 30 .

TR-II vacuum and beam-line components.

stray fields. Magnet power leads and bus baxs were designed so that large currents $( \pm 3000 \mathrm{~A})$ that induce stray fields in the area of the conductor would cancel each other. A section of the power distribution system is shown in Fig. 32, illustrating how the hardware was integrated with the support structure and routed to make a neat and compact, yet accessible, assembly. The 


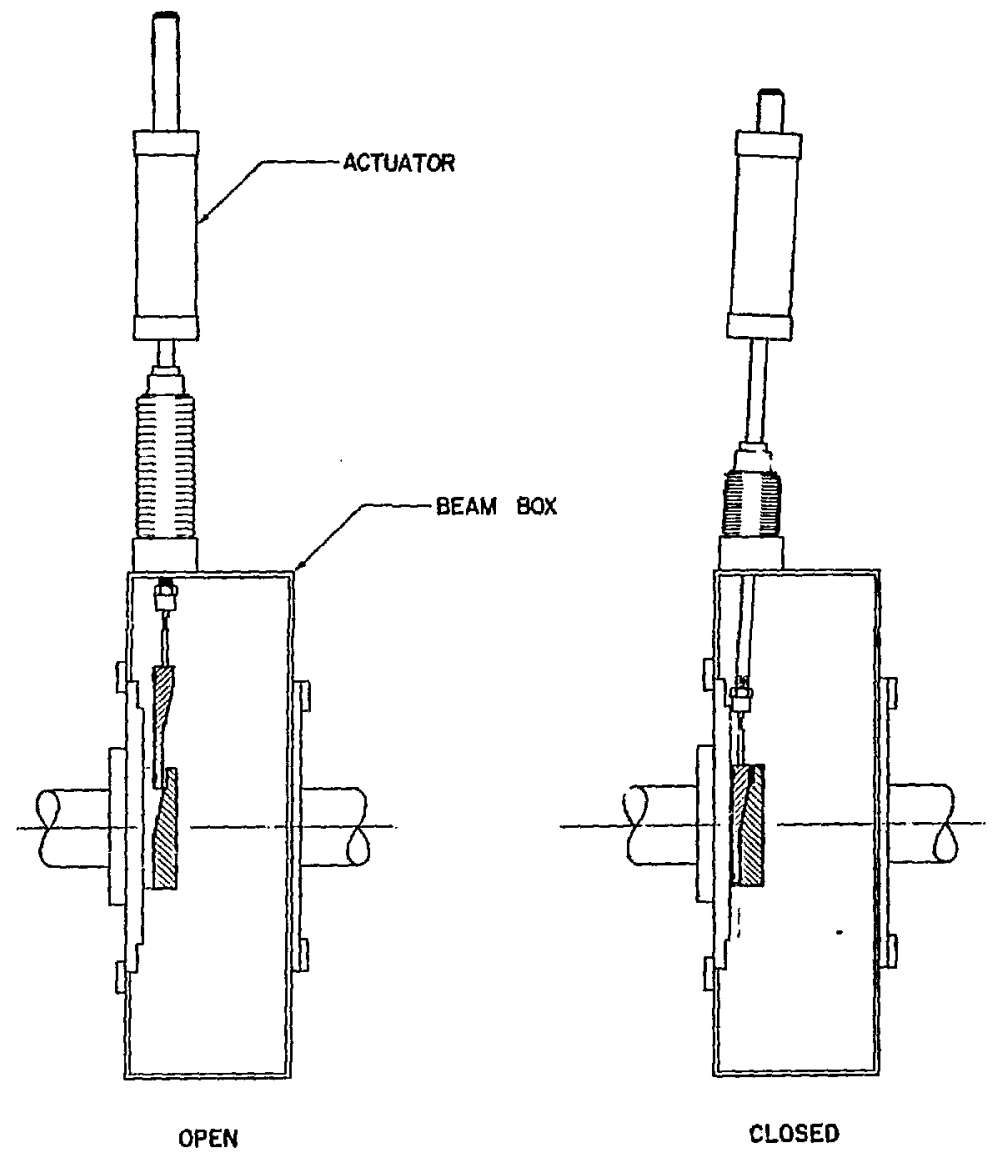

Fig. 31 .

TR-II custom-built isolation valve.

water-cooled jumper leads shown in F1g. 33 were positioned after preliminary alignment had been done. This procedure allowed each lead to be made to the exact required length, not with a long pigtail as is of ten the case for magnet hookup leads.

Figure 3 shows the power schematic for the TR-II bending magnets.

\section{K. TR-II Cooling-Water System}

The TR-II cooling system was designed to remove $1.5 \mathrm{MW}$ of heat, twice the cooling load for the original TR. This increase is primarily the result of the use of more magnets, larger bend angles, and larger apertures. The bucking and 


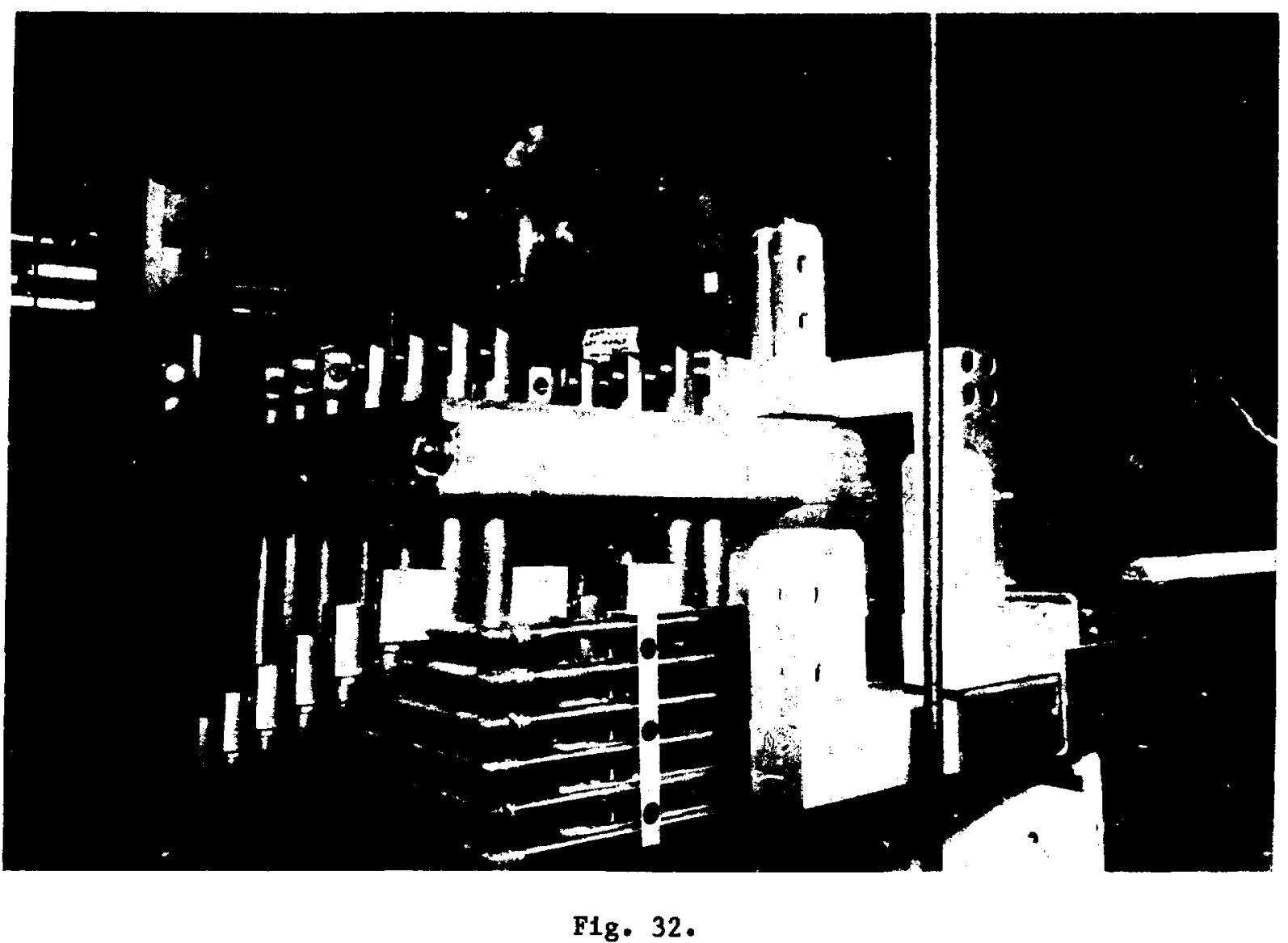

TR-II magnet power distribution.

adding fields to control the $\mathrm{H}^{-}$path length also require considerably more power than does a normal shunt system.

The sector "A" (A02) water system that cooled the original TR runs close to Its maximum capacity. To cool the TR-II 1 t was decided to use the 805-MHz (B02) system because it has extra capacity available. This cholce will allow high-power operation during the summer.

All components in the TR-II were designed to operate with a low (500-kPa) pressure drop cooling water requirement. This selection allowed the use of a low head, high capacity, single stage, centrifugal pump. Since accurate temperature control of the cooling water is not required, an air-operated temperature control system that maintains return water at $\sim 29^{\circ} \mathrm{C}$ was used. This system was used on the original TR. It should continue to provide adequate control. Figure 34 is a schematic of the TR-II cooling-water system. The primary protection for all magnets in TR-II is interlocked with pump power. The 


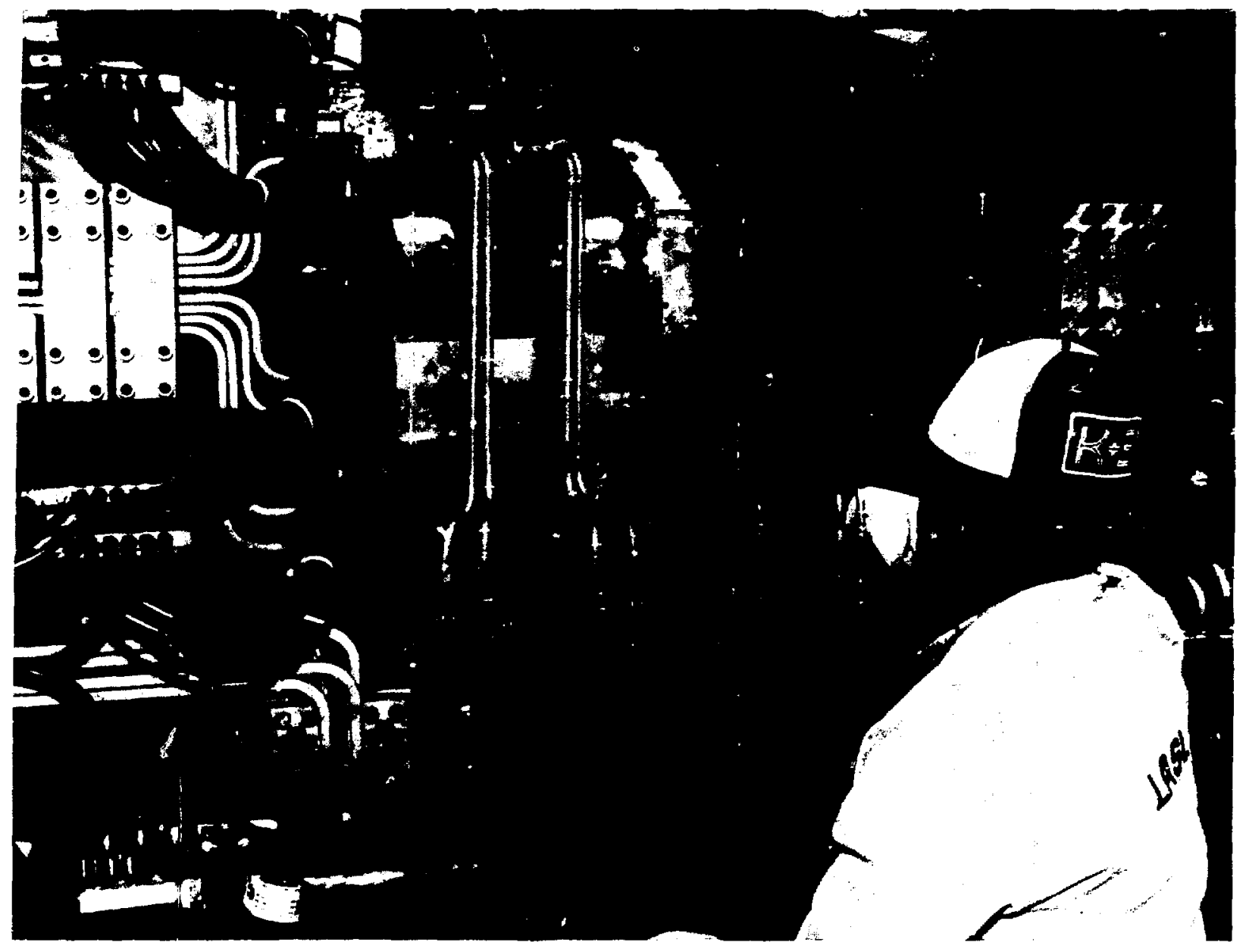

Fig. 33.

TR-II magnet water-cooled power leads.

secondary system utilizes thermal switches that trip the power supplies if high temperatures at the magnets are detected. The flow switch on each component's return line provides an Interlock signal to prevent powering that component without cooling-water flow. The flow interlocks are a back-up safety system. This arrangement is similar to the original TR safety circuit that has proven to be effective in protecting equipment from cooling-system failures. TR-II cooling-system equipment is listed in Appendix $\mathrm{F}$. 


\section{TR-II STAGING AND INSTALLATION}

It was decided early in project planning that preinstallation staging of the complete TR-II would be required. This decision was necessary because of the extreme density of components and the existence of a fixed time window for installation of TR-II in the beam channel. The installation schedule could not allow any time for rework.

The complete TR-II was assembled at the Equipment Test Laboratory (ETL), as shown in Fig. 35. This staging allowed the magnets, bus bar, cooling manifolds, and vacuum pipe to be custom-fitted to the support structure. A mockup of the wireways made it possible to order made-up lengths of water-cooled power cable. The move from ETL to the beam channel was made by removing the magnets and loading the support structure on a lowboy trailer for transporting. The water manifolds, heavy power bus, and part of the magnet mounts remained with the support.

Removal of the old TR to the stage shown in Fig. 36 and installation of the new TR-II to the point shown in Fig. 37 were accomplished in ten working days. Adequate planning, good coordination, and dedicated people made this move a smooth and rapld operation. Once the magnets were in position, the installation of water, power, vacuum, beam diagnostics, and control wiring was started.

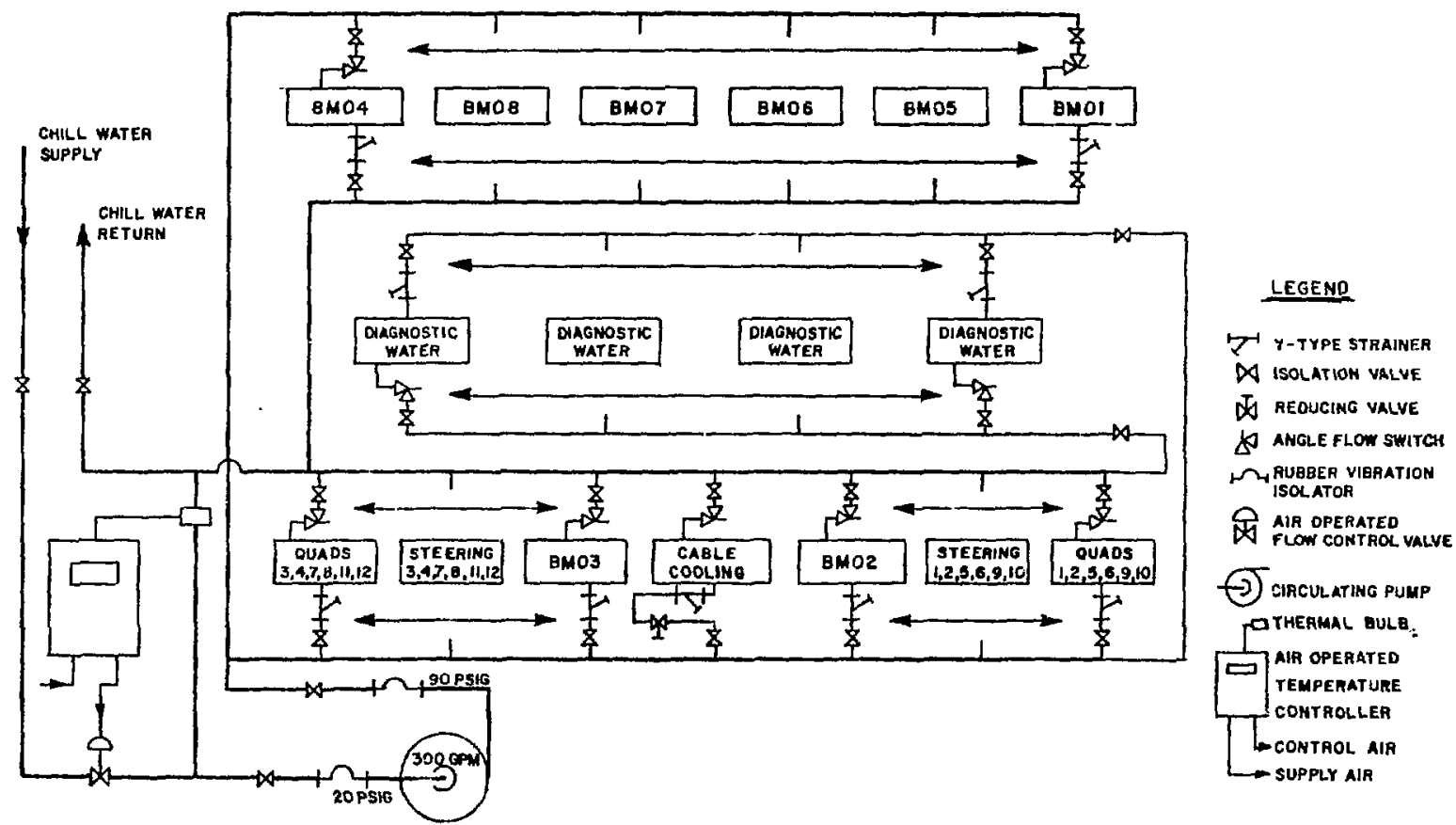

F1g. 34 .

TR-II cooling water schematic. 


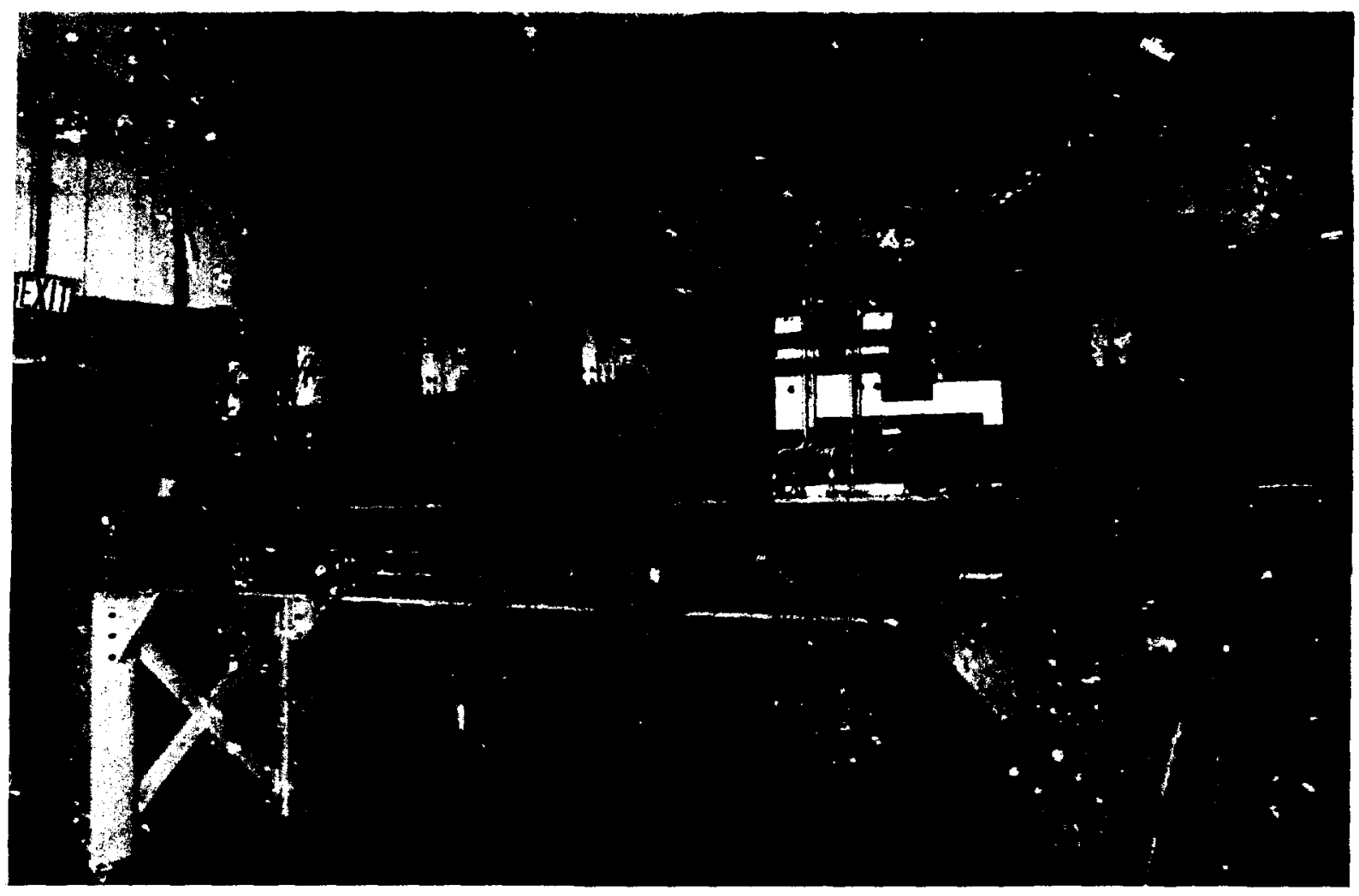

Fig. 35.

TR-II staged at ETL Building.

\section{CONCLUSION}

After completion of the new Transition Region, the power supplies, controls, and interlocks were tested in preparation for the 5 July 1983 turn on, which went quite well. Beam tuning was performed and production beam was delivered to the experimental area on 1 August 1983. Beams have been transported through all three paths, with $\mathrm{H}^{+}$and $\mathrm{H}^{-}$beams delivered through the short and long tracks simultaneous1y. $\mathrm{H}^{+}$beam currents of 900 uA have been successfully transported for production beams. After saveral months of operation, all devices are performing as desired and the alignment seems to be sufficient. At this time (Apri1 1984) no changes in design have been proposed. 


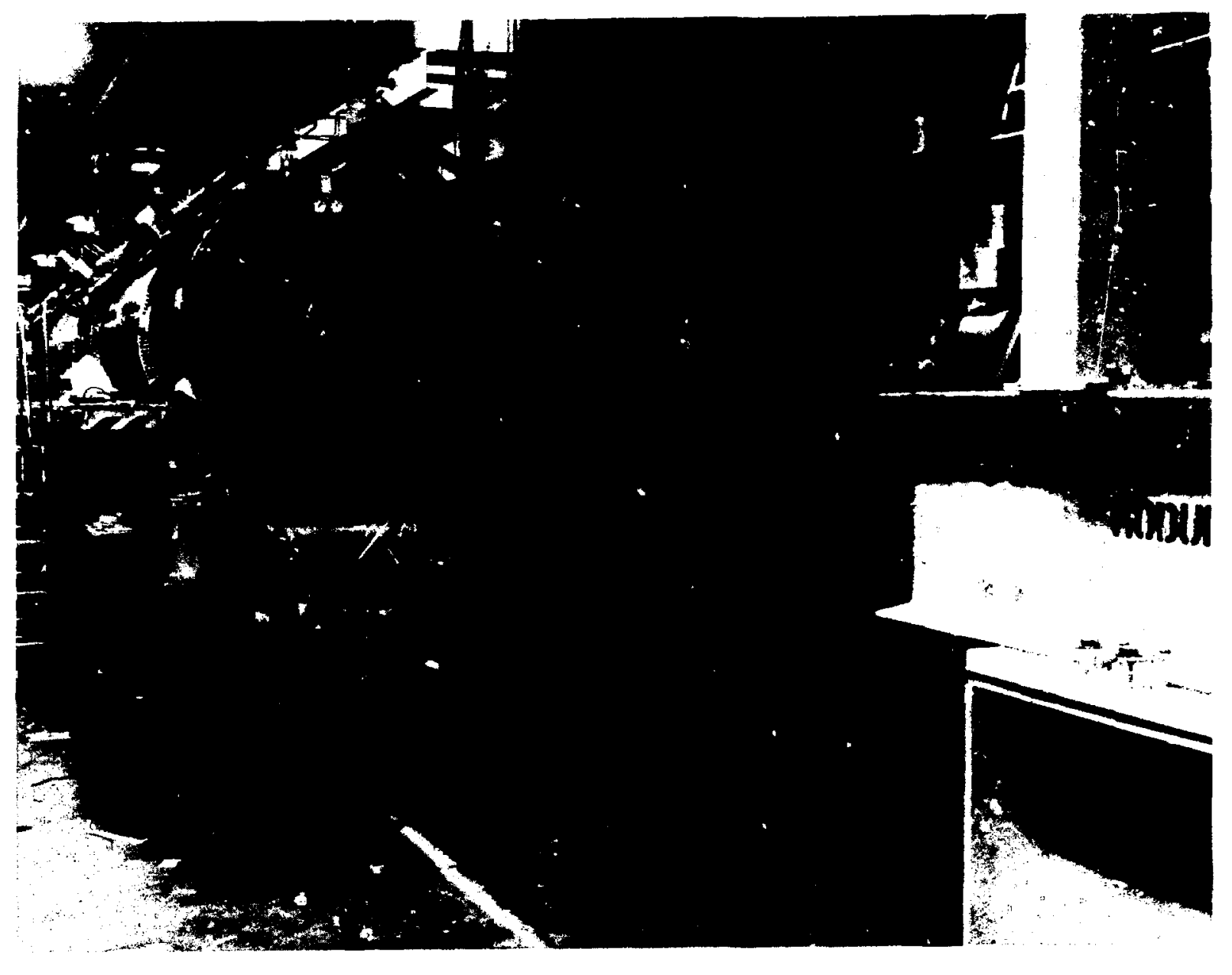

Fig. 36 .

Space for the TR-II In the beam channel. 


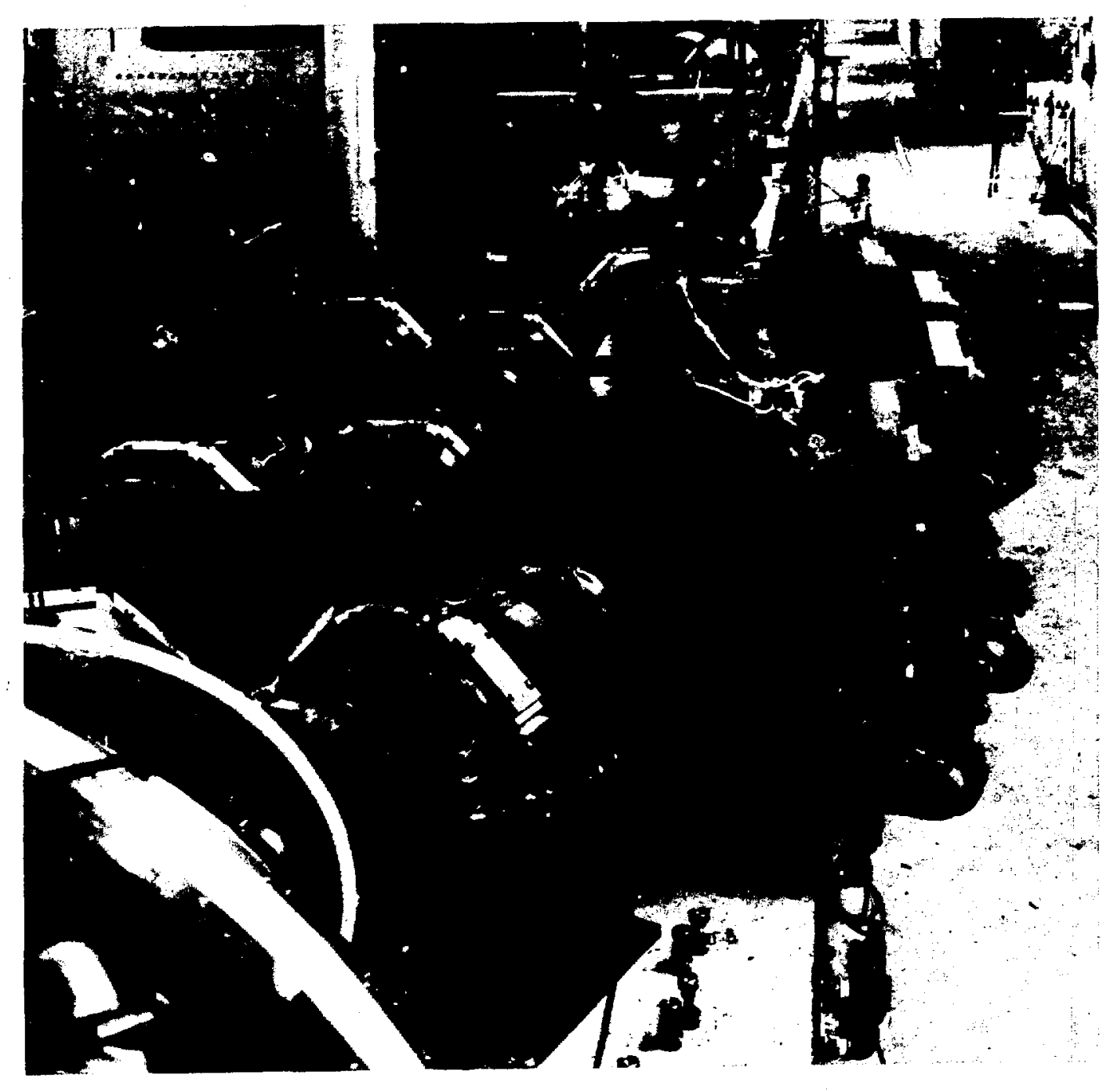

Fig. 37 .

TR-II installed in beam channel. 
VI. ACKNOWLEDGEMENTS

The successful turn on of TR-II was the culmination of effort by many dedicated people. The overall project responsibility was managed by MP 8 with MP-11 suppnrt in the areas of power supplies, beam diagnostics, and vacuum. Special thanks are due Arlene Lopez for complifing and production of this paper. Those people who had major involvement with this project, and their areas of contribution are listed below:

Chester R. Smith
Michae1 J. Burns
Ralph K. Lopez
Steven F. Archuletta
Michael G. Mays
Maynard R. Roberts
Patrick A. McCle1lan
David J. Honaberger
Edward M. Perez
Gilbert Suazo
Clifford Gladwell
Dorwin R. Justice
GIlbert J. Gonzales
Tomas O. Sanchez
Edward R. Weiler
Justo F. Cordova
Edward J. Schneider
Richard Tregellas
Louls Morrison
Bobby Poe \& Vacuum Crew
Edwin Eaton \& MST Plastics
Section

\author{
Drafting \\ Drafting \\ Drafting \\ Magnet Measurement \\ Magnet Measurement \\ Magnet Measurement \\ Magnet Fabrication \\ Magnet Fabrication \\ Magnet Fabrication \\ Cable Trays, Safety Fence, \\ General Fabrication \\ General Fabrication \\ General Fabrication \\ General Fabrication \\ Vacuum Component Welding \\ Installation \& Alignment \\ Installation \& Allgnment \\ Power Supplies \\ Diagnostics \\ Vacuum Installation \\ Vacuum Installation \\ Coll Potting
}

\section{REFERENCES}

1. D. A. Swenson, "The Transition Region," MP-Division internal report MP-3-75 (February 1969).

2. 0. R. Sander, "LAMPF Transition Region," Los Alamos National Laboratory report LA-9315-MS (June 1982).

3. 0. R. Sander, A. A. Browman, and E. D. Bush, Jr., "Redesign of the LAMPF Transition Region," Particle Accelerator Conference, 1981, Proc., IN-IEEE Trans. Nuc1. Sci., V. NS-28, p. 2914-5 (198i). 
4. A. A. Browman, "TR Bending Magnet Description," Los Alamos National Laboratory memo (August 1983).

5. A. A. Browman, "TR II Quadrupole Magnets," Los Alamos National Laboratory memo (Apri1 1983).

APPENDIX A

TR-II DRAWING LIST

$60 \mathrm{Y}-124450$

$60 Y-124451$

$60 \mathrm{Y}-124452$

$60 \mathrm{Y}-124453$

$60 Y-124454$

$60 Y-124455$

$60 Y-124456$

$60 \mathrm{Y}-124457$

$60 \mathrm{Y}-124458$

$60 \mathrm{Y}-124459$

$60 \mathrm{Y}-124460$

$60 \mathrm{Y}-124461$

$60 \mathrm{Y}-124462$

60Y-124463

$60 \mathrm{Y}-124464$

$60 Y-124465$

$60 \mathrm{Y}-124466$

$60 Y-124467$

$60 Y-124468$

$60 Y-124469$

$60 Y-124470$

$60 \mathrm{Y}-124471$

$60 \mathrm{Y}-124472$

$60 Y-124473$

$60 \mathrm{Y}-124474$

$60 \mathrm{Y}-124475$

$60 \mathrm{Y}-124476$

$60 \mathrm{Y}-124477$

$60 \mathrm{Y}-124478$

$60 \mathrm{Y}-124479$

$60 \mathrm{Y}-124480$

$60 \mathrm{Y}-124481$

$60 Y-124482$

$60 \mathrm{Y}-124483$

$60 Y-124484$

$60 \mathrm{Y}-124485$

$60 \mathrm{Y}-124486$

\author{
TR-II Magnetic Effective Lengths \\ TR-II Envelope Drawing \\ TR-II Bending Magnet Iron \\ TR-II Coordinate System \\ TR-II Steering Magnet \\ TR-II Beam Box-09 \& Vacuum Chamber \\ for $B M-05, B M-06, B M-07 \& B M-08$ \\ TR-II Instaliation Drawing \\ TR - Mode1 II Prototype QM Iron \\ TR-II Beam Box 2-80, 10-12 \\ TR-II Support Structure \\ TR-II Alignment Mount - BM \\ TR-II Alignment Mounts BMs, SMs, \& QMs \\ TR-II Potting Form Quad Magnet Coll \\ TR-II Cradle Assembly Group $1 \& 4$ \\ TR-II Cradle Assembiy Group 2 \& 3 \\ TR-II Cradle Assemb]y Group 5-6\& 7-8 \\ TR-II Cradle AssembLy Group 9-10\& 11-12 \\ TR-II Beam Box-1 \& Slow Valve Assembly \\ TR-II Electrical \& Plumbing \\ TR-II Vacuum System \\ TR-II - BM-01\& BM-04 Alignment Mount Filler Plate \\ TR-II Water System Valve Mode Indicator \\ TR-II Gaussmeter (Modifled) \\ TR-II Vacuum Chamber 3M-04 \\ TR-II Vacuum Chamber BM-02\&BM-03 \\ TR-II Inspection F1xture BM-02 through BM-12 \\ TR-II Support \& Alignment Mount for BM-01 \\ TR-II Rotating Coll Quadrupole Magnets \\ TR-II Retaining Ring For BB-01 \\ TR-II Q.M. Feedthru \\ Pier Assembly, $805 \mathrm{MHz}$, Module 5 Upstream \\ TR-II Vacuum Manifold Center Section \\ TR-II Vacuum Manifold \\ TR-II Support and Alignment Stand for BB-13 \\ TR-II Vacuum Chamber BM-01 \\ Potting Form TR-II BM Colls \\ TR-II Steering Magnet Beam Absorber
}


$60 \mathrm{Y}-124487$

$60 \mathrm{Y}-124488$

$60 \mathrm{Y}-124489$

$60 \mathrm{Y}-124490$

$60 Y-124491$

$60 Y-124492$

$60 Y-124493$

$60 \mathrm{Y}-124494$

$60 \mathrm{Y}-124495$

$60 \mathrm{Y}-124496$

$60 Y-124497$

$60 \mathrm{Y}-124498$

$60 \mathrm{Y}-12449$ ?
TR-II Vacuum Tube Support

TR-II Alignment Fixture for Quad Magnets

TR-II Alignment Fixture for Quad Magnets

TR-II Short Track Energy Absorber

TR-II Long Track Energy Absorber

TR-II Bending Magnet-Water \& Elec. Jumper Blocks

TR-II Vacuum Manifold Center Support

TR-II Beam Box Flange

TR-II Manifold to Beam Pipe Adaptor

TR-II Beam Pipe

TR-II Manifold to Beam PIpe Adaptor

TR-II Vacuum PIpe Support

TR-II Gaussmeter Mod. II

\section{APPENDIX B}

\section{"AIMS" APPLICATION PROGRAMS}

\section{Application Programs*}

1. Manual Measure

Normal routine outputs, coordinates distance between points \& point ID.

2. Auto-Measure Same as Manual but defaults name to event counter for rapid measuring.

3. Average Multi-Peadings Used when target is difficult to seo, averages repeated readings.

4. Laser-Mirror Outputs azimuth and elevation angles of object surface. With the aid of small laser computes direction of the normal to a mirror surface.
5. Paraboloids

For antenna manulacture and $\mathrm{QA}$

Facilitates calibration of parabolic surface.

6. Transform

Changes coordinate system to new orientalion.

7. Set-Point

Used to place object to target at predetermined coordinate position.

8. Compute Length Outputs length between any two previously measured points.

9. Find Circle Center Given three points, calculates coordinates of circle center.
10. Sphere Size or deviation of Spheroid.

11. Cylinder Size of deviation of Cylinder (tank).

12. Out ol Round Deviation of circle points.

13. Hidden Point To compute location of point which cannot be seen by theodolites.

14. Delta X. Y. Z Computes difference in $X, Y, Z$ between two successively measured points.

Subject to change or modification without notice. 


\section{APPENDIX $C$ \\ RECAPITULATION OF DATA WITH ERRORS GIVEN \\ NOTE: Z DATA ARE INVALID}

FOLLOWING IS A RECAPITULATTON FOR NOMBERED TARGETS OF THE BLUEPRINT NOMINAL X, DIMNSIONS, AND THE ERRORS FROM THOSE NOMINALS. THE LAST COLUMN, UNCERTAINTY ANGLE IN DECIMAL DEGREES, REFLECTS THE QUALITY OF THE POINT TO EACH TARGET. DELTA IS THE DISTANCE TO THE PREVIOUS TARGET, OR ELGE THE DEVIATION FROM A FITTED MATHEMATICAL SHAPE.

\begin{tabular}{|c|c|c|c|c|c|c|c|c|c|c|}
\hline VENT & $\underline{\mathrm{X}}$ & $X$ error & $\underline{Y}$ & Y error & $\underline{Z}$ & 2 error & $\begin{array}{l}\text { UNC ANG } \\
\text { IDENTIE }\end{array}$ & YING NL & $\mathrm{d} / 0$ & I COMMENTS \\
\hline 80 & -27.8976 & -21.9666 & 79.4326 & +79.4326 & -10.3886 & -33.8596 & 0.0004 & 0.0014 & & 400 TARGE \\
\hline 81 & 190.5609 & -21.9751 & 78.4842 & +78.4842 & -10.3887 & -33.8597 & 0.0004 & 0.0016 & 218.461 & 500 TARGE \\
\hline 82 & -5.9310 & & 0.0000 & & 23.4710 & & 0.0000 & 0.0000 & & RESET \\
\hline 83 & 212.5296 & & -0.0000 & & 23.4709 & & 0.0000 & 0.0000 & & RESET \\
\hline 84 & 14.3864 & +0.0004 & -0.0033 & -0.0033 & 10.0789 & +0.2719 & 0.0004 & -0.0014 & & $101 \mathrm{BM}-1$ \\
\hline 86 & -5.9310 & -0.0000 & 0.0000 & +0.0000 & 23.4710 & -0.0000 & 0.0004 & 0.0014 & & 400 TARGE \\
\hline 87 & 28.3833 & -0.0027 & -0.0017 & -0.0017 & 10.0705 & -0.2636 & 0.0003 & -0.0008 & 36.838 & 102 BM-1 \\
\hline 88 & 36.7412 & -0.0028 & 5.4873 & -0.0037 & 6.6865 & +2.0645 & 0.0010 & -0.0028 & 10.5563 & $124 \mathrm{SM}-1$ \\
\hline 89 & 42.9747 & -0.0053 & 7.7617 & +0.0007 & 7.5003 & +1.6883 & 0.0011 & -0.0032 & 6.6852 & $125 \mathrm{QM}-1$ \\
\hline 92 & 66.6460 & -0.0030 & 13.7250 & -0.0030 & 7.1829 & +0.2509 & $0.00 n 7$ & -0.0019 & & 105 BM-2 \\
\hline 93 & 52.6444 & -0.0036 & 13.7241 & -0.0039 & 7.1829 & +0.2509 & 0.0003 & -0.0008 & 14.0016 & 104 BM-2 \\
\hline 100 & 72.6826 & +0.0016 & 13.7269 & -0.0001 & 6.6773 & -0.0077 & 0.0002 & -0.0005 & +.0063 & 126 SM-2 \\
\hline 101 & 80.2473 & +0.0033 & 13.7286 & +0.0016 & 7.5056 & +1.6936 & 0.0012 & -0.0030 & 7.6099 & $127 Q M-2$ \\
\hline 104 & 122.9273 & -0.0107 & 13.7233 & -0.0037 & 7.4980 & +1.6860 & 0.0033 & & & $128 Q M-3$ \\
\hline 105 & 130.4991 & -0.0009 & 13.7255 & -0.0015 & 6.6983 & +0.0133 & 0.0003 & 0.0008 & 7.6139 & $129 \mathrm{QM}-3$ \\
\hline 106 & 136.5304 & -0.0036 & 13.7241 & -0.0039 & 7.1860 & +0.2560 & 0.0002 & 0.0005 & 6.051 & 107 BM-3 \\
\hline 107 & 150.5319 & -0.0021 & 13.7287 & +0.0007 & 7.1843 & +0.2543 & 0.0006 & -0.0017 & 14.0015 & 108 BM-3 D \\
\hline 109 & 60.2041 & +0.0021 & 7.7635 & +0.0025 & 7.4935 & +1.6815 & 0.0006 & -0.0016 & +.0081 & $130 Q M-4$ \\
\hline 110 & 166.4335 & -0.0035 & 5.4883 & -0.0027 & 6.6958 & +2.0738 & 0.0007 & -0.0019 & 6.6797 & $131 \mathrm{SM}-4$ \\
\hline 111 & 174.7983 & -0.0027 & -0.0034 & -0.0034 & 10.0770 & +0.2700 & 0.0013 & -0.0040 & 10.5623 & $110 \mathrm{BM}-4 \mathrm{U}$ \\
\hline 114 & 188.8073 & +0.0093 & -0.0010 & -0.0010 & 10.0715 & +0.2645 & 0.0010 & -0.0034 & +.0058 & $111 \mathrm{BM}-4$ \\
\hline 116 & 165.6948 & +0.0008 & -5.7662 & -0.0042 & 6.7122 & +2.0902 & 0.0001 & -0.0002 & +.0040 & $139 \mathrm{SM}-8$ \\
\hline 117 & 146.2029 & -0.0041 & -12.8528 & +0.0022 & 7.4932 & +1.6812 & 0.0001 & -0.0002 & 20.7549 & $136 \mathrm{QM}-7$ \\
\hline 118 & 138.8734 & -0.0086 & -18.0750 & -0.0000 & 7.1814 & +0.2484 & 0.0005 & -0.0011 & 9.0051 & $123 \mathrm{BM}-8 \mathrm{D}$ \\
\hline 119 & 124.8779 & -0.0041 & -18.0767 & -0.0017 & 7.1853 & +0.2523 & 0.0001 & 0.0001 & 13.9955 & $122 \mathrm{BM}-8 \mathrm{C}$ \\
\hline
\end{tabular}




\section{APPENDIX D}

TR-II VACUUM SYSTEM PARAMETERS

\begin{tabular}{|c|c|c|c|c|c|}
\hline $\begin{array}{l}\text { Material } \\
\text { in Vacuum } \\
\text { Speed System }\end{array}$ & $\begin{array}{l}\text { Est1mated } \\
\text { Outgas Rate } \\
\text { torr } 1 / \mathrm{cm}^{2} / \mathrm{s} \\
\end{array}$ & $\begin{array}{l}\text { Surface } \\
\text { Area } \mathrm{cm}^{2} \\
\end{array}$ & $\begin{array}{l}\text { Generated } \\
\text { Gas Load } \\
\text { torr } 1 / \mathrm{s} \\
\end{array}$ & $\begin{array}{l}\text { Pumping } \\
\text { Speed Required } \\
\text { for } 3 \times 10^{-5} \\
\text { torr } 1 / \mathrm{s} \\
\end{array}$ & $\begin{array}{l}\text { Ion Pump N2 } \\
\text { Rated Speed } \\
\text { for } 3 \times 10^{-6} \\
\text { torr } 1 / \mathrm{s}\end{array}$ \\
\hline 304 SS & $1 \times 10^{-10}$ & 70,000 & $7 \times 10^{-6}$ & 2 & 11 \\
\hline $6061 \mathrm{AL}$ & $2 \times 10^{-9}$ & 10,000 & $2 \times 10^{-5}$ & 7 & 39 \\
\hline $\begin{array}{l}\text { Kapton } \\
\text { Insulation }\end{array}$ & $3 \times 10^{-8}$ & 16,000 & $5 \times 10^{-4}$ & 167 & 928 \\
\hline G-10 & $1 \times 10^{-7}$ & 4,000 & $4 \times 10^{-4}$ & 133 & 739 \\
\hline TOTAL & & 100,000 & $9.27 \times 10^{-4}$ & 309 & 1717 \\
\hline
\end{tabular}

APPENDIX E

TR-II POWER SUPPLIES

1. Bending magnet (two power supplies)

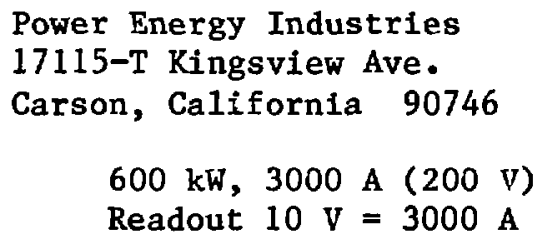

2. Quad magnets (eight power supplies)

Christle Laboratories Inc.

2121 W. 117th Street

Cleveland, Ohio 44411

$15 \mathrm{~kW}, 1000 \mathrm{~A}(15 \mathrm{~V})$

Readout $100 \mathrm{mV}=\mathrm{A}$ 
Hookup convention: At the back of the power supply, horizontal bus bars gtve a hortzontal focusing magnet (for + particles). The ammeter readings deflect to the right.

\section{Steering magnets}

The steering magnets are powered by a LAMPF mult1-channel bipolar-output power supply. Each channel is capable of \pm 250 A. Power supply currents are measured with shunts that produce a 100-mV signal at $250 \mathrm{~A}$. Signals are amplified at the power supply and sent to CCR where a readout of $10 \mathrm{~V} \approx 250 \mathrm{~A}$ is used.

Each power supply channel is set up so that a control potentlometer set: Ing of 500 counts gives zero output. For a positive beam $\left(\mathrm{H}^{+}\right)$, control potentlometer settings above 500 counts steer the beam up when used for vertical steering. When used for horizontal steering, settings above 500 counts steer the beam to the right.

\section{APPENDIX $F$}

TR-II COOLING-SYSTEM COMPONENTS

1. Taylor Instruments Process Control Division Sybron Corporation 95 Ames Street Rochester, New York 14601

Taylor 440R Serles pneumatic indicating controller.

2. Transamerica Delaval Inc.

Gems Sensor Division

Plalnville, Connecticut 06062

GEMS FS400 bronze flow switches 
3. Robert Shaw Controls Company

Fulton Sylphon Division

Box 400

Knoxv111e, Tennessee 37901

Model VC-230 - 1-1/2 inch diaphragm control valve

4. Aurora Pump

800 Alrport Road

North Aurora, I111nols 60542

Aurora pump mode1 361A, S1ze $2 \times 2-1 / 2$ X7A, 20 H.P., 160 foot heat at $300 \mathrm{GPM}$.

5. Texas Instruments

34 Forrest St.

Attleboro, Massachusetts 02703

Klixon serles 4344 thermostat, stud mount 